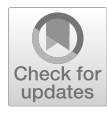

Cite as

Nano-Micro Lett.

(2022) 14:41

Received: 22 July 2021

Accepted: 12 November 2021

Published online: 3 January 2022

(C) The Author(s) 2021

\section{From Bench to the Clinic: The Path to Translation of Nanotechnology-Enabled mRNA SARS-CoV-2 Vaccines}

\author{
Diana O. Lopez-Cantu ${ }^{1,2,3,4}$, Xichi Wang ${ }^{1,2,3,5}$, Hector Carrasco-Magallanes ${ }^{6,7}$, \\ Samson Afewerki ${ }^{1,2}$, Xingcai Zhang ${ }^{8,9}{ }^{凶}$, Joseph V. Bonventre ${ }^{1,2,3}$, \\ Guillermo U. Ruiz-Esparza ${ }^{1,2,3} \bowtie$
}

\title{
HIGHLIGHTS
}

- Pfizer-BioNTech's and Moderna's nanotechnology-enabled mRNA vaccines are the first of its kind to be approved for human use.

- The COVID-19 pandemic has changed our lives and although SARS-CoV-2 has caused irreversible health, social and economic damage, continuous and extensive efforts world-wide were essential to reduce its deleterious effects.

\begin{abstract}
During the last decades, the use of nanotechnology in med icine has effectively been translated to the design of drug delivery systems, nanostructured tissues, diagnostic platforms, and novel nanomaterials against several human diseases and infectious pathogens. Nanotechnology-enabled vaccines have been positioned as solutions to mitigate the pandemic outbreak caused by the novel pathogen severe acute respiratory syndrome coronavirus 2 . To fast-track the development of vaccines, unprecedented industrial and academic collaborations emerged around the world, resulting in the clinical translation of effective vaccines in less than one year. In this article, we provide an overview of the path to translation from the bench to the clinic of nanotechnology-enabled messenger ribonucleic acid vaccines and examine in detail the types of delivery systems used, their mechanisms
\end{abstract}

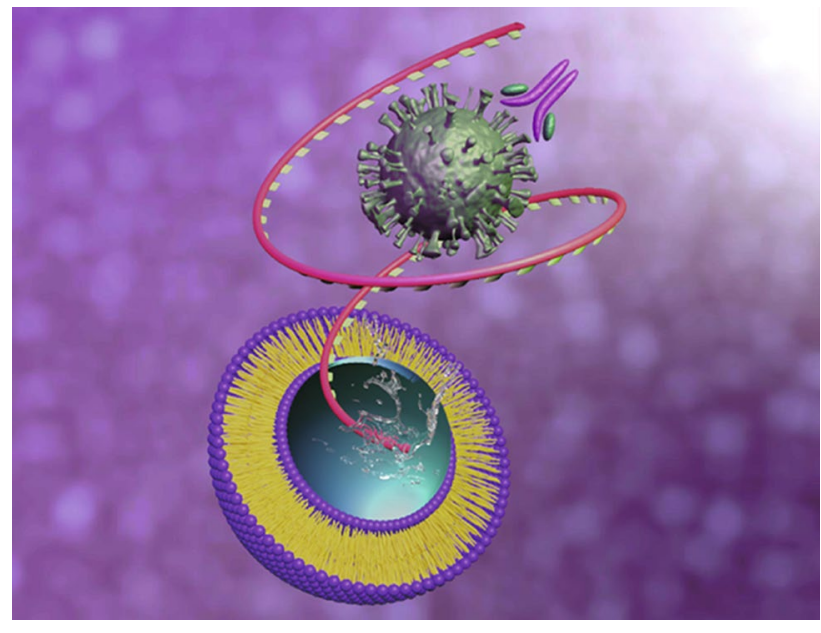
of action, obtained results during each phase of their clinical development and their regulatory approval process. We also analyze how nanotechnology is impacting global health and economy during the COVID-19 pandemic and beyond.

KEYWORDS Nanovaccines; mRNA; Coronavirus; SARS-CoV-2; COVID-19

\footnotetext{
Xingcai Zhang, xingcai@mit.edu; Joseph V. Bonventre, jbonventre@bwh.harvard.edu; Guillermo U. Ruiz-Esparza, gruizeh@bwh.harvard.edu; gruizeh@mit.edu

1 Division of Engineering in Medicine, Department of Medicine, Brigham and Women's Hospital, Harvard Medical School, Boston, MA 02115, USA

2 Division of Health Sciences and Technology, Harvard University - Massachusetts Institute of Technology, Boston, MA 02115, USA

3 Division of Renal Medicine, Department of Medicine, Brigham and Women's Hospital, Harvard Medical School, Boston, MA 02115, USA

4 Tecnologico de Monterrey, School of Engineering and Sciences, 64849 Monterrey, NL, Mexico

5 Department of Cardiovascular Surgery, Union Hospital, Tongji Medical College, Huazhong University of Science and Technology, Wuhan 430022, People's Republic of China

${ }^{6}$ Harvard T.H. Chan School of Public Health, Boston, MA 02115, USA

7 Tecnologico de Monterrey, School of Medicine and Health Sciences, 64849 Monterrey, NL, Mexico

8 John A. Paulson School of Engineering and Applied Sciences, Harvard University, Cambridge, MA 02138, USA

9 School of Engineering, Massachusetts Institute of Technology, Cambridge, MA 02139, USA
} 


\section{Introduction}

In December 2019, the severe acute respiratory syndrome coronavirus 2 (SARS-CoV-2) was discovered, which then precipitated the emergence of the largest global pandemic since the 1918 Spanish flu which was caused by the Hemagglutinin Type 1 and Neuraminidase Type 1 (H1N1) influenza A virus [1]. The origin of SARS-CoV-2, the virus responsible for coronavirus disease 19 (COVID-19), was traced to bats and pangolins, two mammals that serve as major reservoirs for various types of coronaviruses (CoVs), and many have concluded that human transmission possibly resulted from close interactions with one or both species, nevertheless, more evidence is necessary to confirm this hypothesis [2]. On March 11, 2020, the World Health Organization (WHO) officially categorized this disease as a global pandemic as it spread over the world causing death and economic devastation [3].

Within weeks after the outbreak of SARS-CoV-2 began, a myriad of public health measures that include lockdowns, testing, contact tracing, and hygiene campaigns, were implemented in several countries to control the spread of the virus; nevertheless, millions of people have been infected, and an unprecedented amount of deaths have occurred around the world [4]. Consequently, global financial markets have been very unstable, millions of people have lost their jobs, and a health and economic crisis has emerged. Based on this sanitary emergency, innovative solutions became urgently needed to curtail the spread of SARS-CoV-2.

In recent years, nanotechnology has been widely used to solve some of the most pressing challenges of modern medicine, as it offers the opportunity to modify and manipulate matter at the nanoscopic scale to generate innovative therapeutic, diagnostic, or theranostic platforms [5]. These technologies include drug delivery nanosystems, nanosensors, nanostructured hydrogels, nanoengineered tissues, and nanovaccines. Nanotechnology has played an important role in the response to the COVID-19 crisis, as various nanoparticlebased vaccines have emerged from several companies around the world. Alliances across industrial (Moderna, Pfizer-BioNTech) and governmental settings allowed the acceleration in the development and clinical translation of nanotechnologyenabled SARS-CoV-2 vaccines. Previously, the development of nano-sized particles formulated to transport antigenic components that induce immune responses has been successfully implemented at the preclinical stage for various applications, such as cancer and some infectious diseases including severe acute respiratory syndrome (SARS) and Middle East respiratory syndrome (MERS) [6]. Nanoparticle-based approaches can achieve targeted delivery of viral proteins or genetic material to antigen-presenting cells (APCs) causing controlled immunogenic responses [7]. Immature APCs uptake nanoparticles (NPs) via phagocytosis or endocytosis and migrate to the closest lymph node through the lymphatic system while undergoing a process of maturation. Once fully matured, APCs complete antigenic presentation on their membrane, $\mathrm{CD} 4^{+}$and $\mathrm{CD} 8^{+} \mathrm{T}$ cells are activated, and immunity is produced to target a specific pathogen (Fig. 1) [8].

In this review, we present an overview of the clinical translation of SARS-CoV-2 messenger ribonucleic acid (mRNA) nanotechnology-enabled vaccines, by exploring in detail their mechanism of action and clinical develpopment during the COVID-19 pandemic.

\section{Coronaviruses}

CoVs are single-stranded ribonucleic acid (RNA) viruses from the Coronaviridae family, with a distinctive crownlike membrane envelope composed of spike glycoproteins localized into their surface [9]. Four genera of CoVs exist: alphacoronavirus, betacoronavirus, gammacoronavirus, and deltacoronavirus [10]. To date, seven CoVs are known to affect humans, 229E and NL63 from the alphacoronavirus genus, and HKU1, OC43, MERS-CoV, SARS-CoV and SARS-CoV-2 from the betacoronavirus genus [11]. Four main structural proteins, essential for the complete assembly of the viral particle are encoded by the coronaviral genome: the spike $\mathrm{S}$ protein, the nucleocapsid N protein, the membrane $\mathrm{M}$ protein, and the envelope $\mathrm{E}$ protein (Fig. 2a) [12]. Each protein has a specific function: the $\mathrm{S}$ protein mediates virus adherence to the host cell receptors and subsequent fusion; the $\mathrm{N}$ protein binds to the $\mathrm{CoV}$ RNA genome, arranges the nucleocapsid and participates in the viral replication cycle; the $\mathrm{M}$ protein forms the main structural part of the viral envelope and interacts with all other structural proteins; and the E protein, the smallest integral membrane structural protein incorporated in the viral envelope, is important for the virus production and maturation [13]. The S protein of SARS-CoV-2 consists 


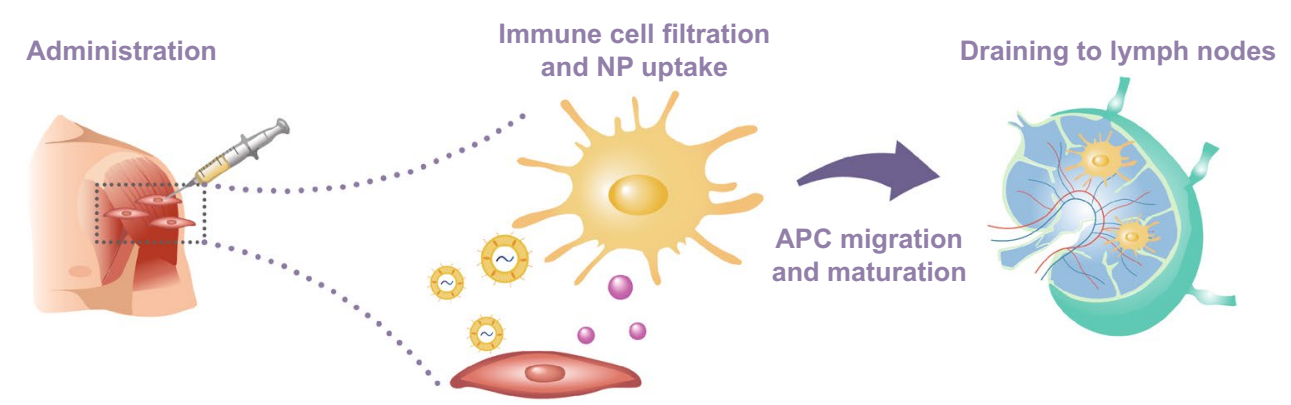

Fig. 1 Schematic representation of vaccine administration, nanoparticle uptake by immature APCs, and subsequent migration to lymph nodes through the lymphatic system

of two subunits: the $\mathrm{S} 1$ subunit contains a receptor-binding domain (RBD) that binds to angiotensin-converting enzyme 2 (ACE2) on the surface of host cells, whereas the S2 subunit mediates fusion between the membranes of the virus and the host cell (Fig. 2a) [14].

SARS-CoV-2, the causative pathogen of COVID-19, has produced a global pandemic due to a highly infectious mechanism based on the co-expression of TMPRSS2 and ACE2 receptors on the cellular membrane of host cells [15] (Fig. 2b). Although ACE2 receptor is expressed on respiratory epithelial human cells, ACE2 is not limited to the lungs, and extrapulmonary spread of SARS-CoV-2 in ACE2-positive tissues has been observed, including the gastrointestinal tract [16-19]. In addition, it has been observed that apical cilia on airway cells and microvilli on type II pneumocytes may be important to facilitate SARSCoV-2 viral entry [20]. SARS-CoV-2 infection is assisted by TMPRSS2, a cellular serine protease, by two independent mechanisms: cleavage of $\mathrm{S}$ glycoprotein to activate host entry, and proteolytic cleavage of ACE2 to promote viral uptake $[19,21,22]$. The priming of the $S$ protein by TMPRSS 2 or other proteases is followed by the affinity, binding of the viral S1 protein domain to the ACE2 receptor, and cellular internalization initiated by plasma membrane fusion and acidic-pH-dependent endocytosis $[19,23]$. Intracellular replication is then facilitated by RNA-dependent polymerases, and assembly of new viral nucleocapsids from genomic RNA and N proteins occurs in the cytoplasm, whereas new particles are produced by the synergistic action of both the endoplasmic reticulum and the Golgi compartments [14]. Lastly, assembly of the genomic RNA and structural proteins into new viral particles leads to their release via exocytosis [14, 24, 25].
The evolution of SARS-CoV-2 has led to the emergence of multiple variants containing amino acid mutations, some of which have been classified as 'variants of concern' (VOC) that impact virus characteristics, including transmissibility and antigenicity [26]. Reports from several countries on the identification of VOCs (United Kingdom-B.1.1.7 [alpha], South Africa-B.1.351 [Beta], Japan/Brazil—P.1 [Gamma], India-B.1.617.2 [Delta]) and variants of interest (Peru-C.37 [Lambda], Colombia-B.1.621 [Mu], U.S.A.-B.1.427 and B.1.429 [Epsilon]), confirm amino acid substitutions and/or deletions acquired in key antigenic sites, such as the RBD and N-terminal domain (NTD) of the S protein, which facilitate viral cell entry [27-32]. Evidence has shown that some of these mutations (N501Y, particularly) are convergent, arisen independently in different lineages (B.1.351, P.1 [sublineage of B.1.1.28]) [26]. Although no significant evolutionary changes occurred approximately 11 months after the emergence of SARS-CoV-2 in late 2019, multiple mutations were identified since late 2020, and novel lineages are expected to emerge for the duration of the COVID-19 pandemic [26].

Clinical manifestations of COVID-19 may include flulike symptoms such as cough, fever, and fatigue to more serious clinical consequences including shortness of breath, anosmia, pneumonia, coagulopathy, acute kidney injury, and accelerative inflammation referred to as a cytokine storm [33]. Other manifestations have been reported in the gastrointestinal tract, liver, heart, skin, and central nervous system [34]. High mortality rate and clinical complications of COVID-19 are particularly associated with advanced age, and multiple co-morbidities such as obesity, hypertension, diabetes, and heart disease [35]. As the world faced a fast-evolving and highly contagious threat, innovative 
(a)

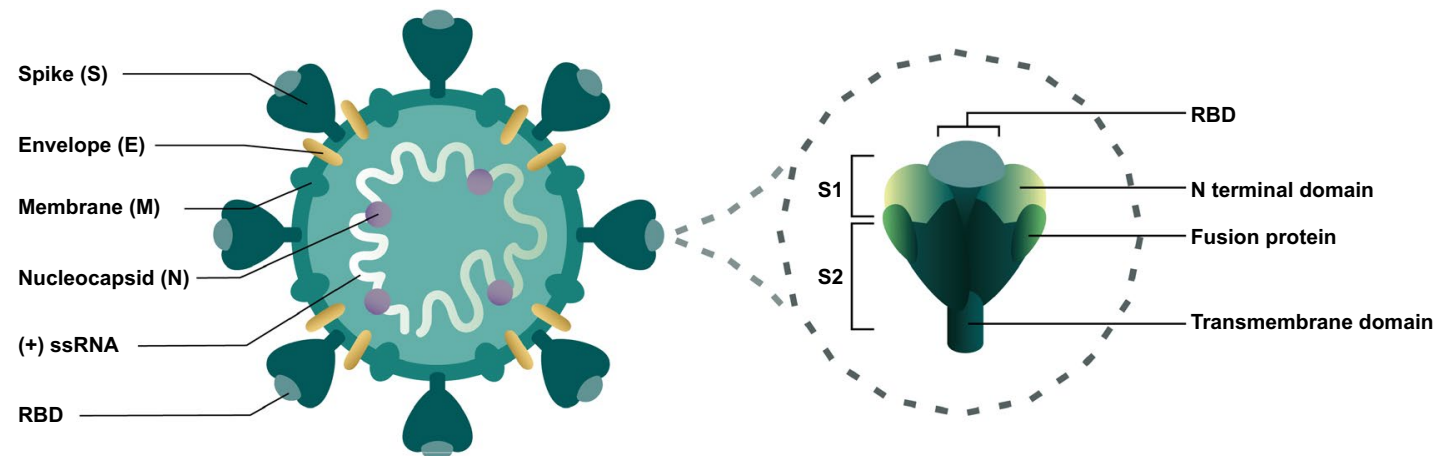

(b)

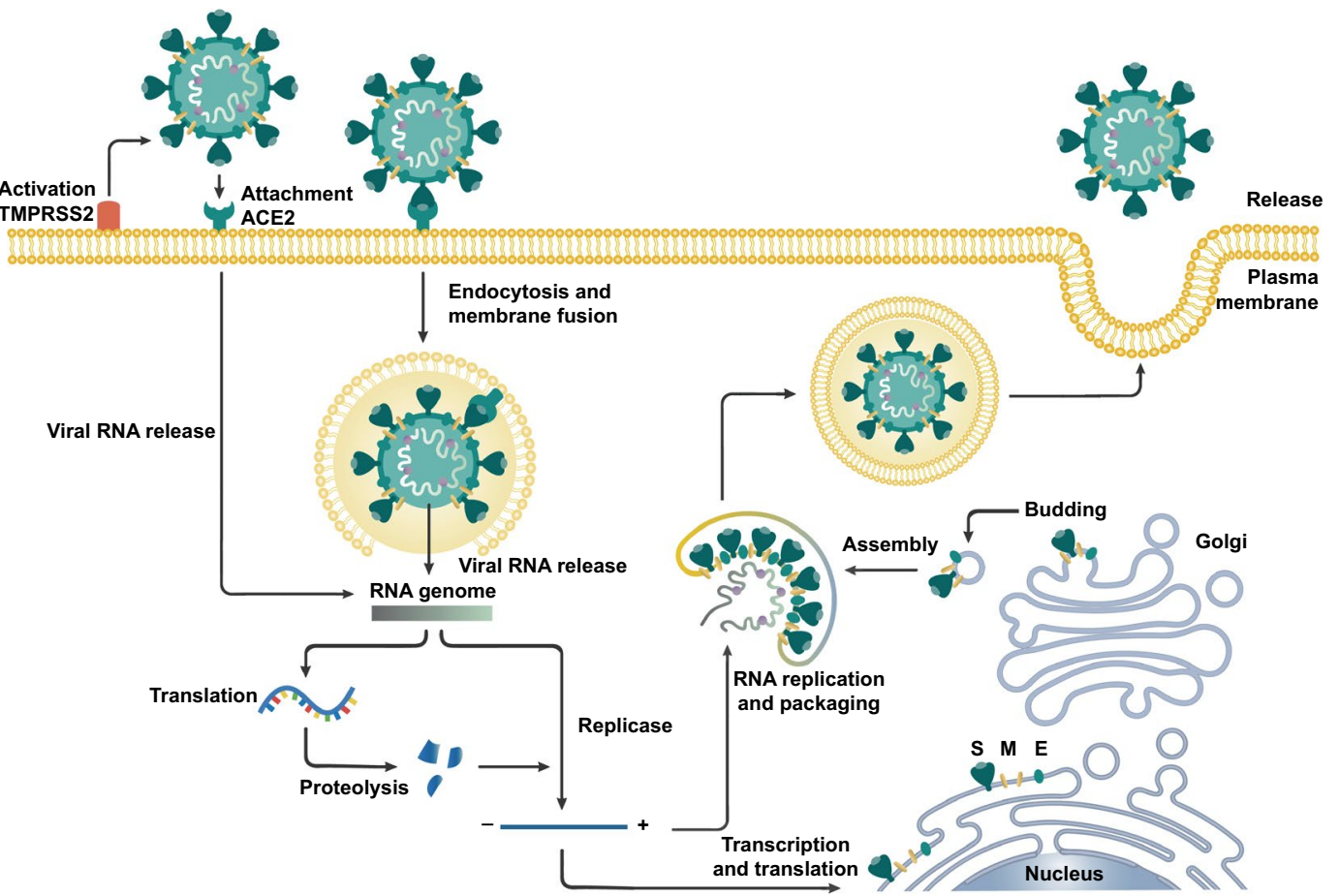

Fig. 2 a Schematic representation of SARS-CoV-2 and spike glycoprotein main structural features. b The viral replication cycle initiates by the activation of the serine protease TMPRSS2 and angiotensin-converting enzyme 2 (ACE2) receptors

approaches were crucial to develop effective vaccines with the aim to suppress the pandemic and decrease mortality.

\section{Nanotechnology as a Tool to Develop Vaccines}

During the last decades, nanotechnology has enabled the development of candidate vaccines for the effective delivery of genetic material and antigenic proteins with high specificity through various administration routes (i.e., oral, intramuscular, intranasal, intradermal, and subcutaneous) [36-41]. Nanovaccination delivery systems have been developed in different forms and can be classified in several categories based on their composition: lipid, polymeric, inorganic, and virus-like nanoparticles (VLNPs) (Fig. 3) [42, 43]. Each class of nanoparticle contains multiple subclasses, with various advantages and disadvantages regarding cargo, delivery, and patient response.

\subsection{Lipid-Based Nanoparticles}

Lipid-based nanoparticles have been the most common class of nanomedicines approved by the U.S. Food and Drug Administration (FDA) [44]. Lipid-based nanoparticles are 
excellent platforms for the encapsulation of diverse hydrophobic or hydrophilic therapeutics, including small molecules, proteins, and nucleic acids. Their multiple advantages include formulation and synthesis simplicity, self-assembly, biocompatibility, and high bioavailability [45]. Common fabrication techniques for lipid-based nanocarriers are highpressure homogenization, high-speed stirring, ultrasonication, emulsion/solvent evaporation, double emulsion, phase inversion, and solvent injection [46].

Lipid-based NPs are divided into several types of systems: liposomal NPs, composed of a lipid bilayer enclosing a hydrophilic core; lipid nanoparticles (LNPs), liposome-like structures with diverse morphologies that usually form an inverse micelle within the core to encapsulate hydrophilic agents; and solid lipid nanoparticles (SLNPs) composed of a lipid monolayer enclosing a solid lipid core [47]. Gene delivery systems often use LNPs to encapsulate nucleic acids in spherical vesicles composed of several materials: ionizable or cationic lipids, helper lipids, and polyethylene glycol (PEG) [48]. Ionizable lipids, which are neutral at physiological $\mathrm{pH}$ and positively charged at low $\mathrm{pH}$, are embedded in the micellar structure of LNPs to complex with negatively charged genetic material, aid endosomal escape, and protect against nuclease-mediated degradation [49, 50]. Helper lipids such as distearoylphosphatidylcholine and cholesterol, promote cell membrane binding and provide structural rigidity. Because LNPs can be rapidly taken up by the reticuloendothelial system, PEG is commonly used to decorate the NP surface to increase bioavailability in the human body [51].

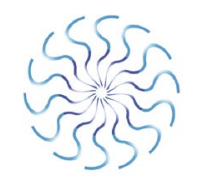

Polymeric

Micelle

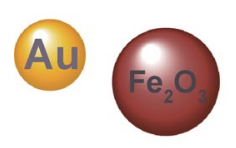

Metallic Nanoparticle

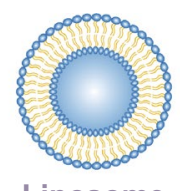

Liposome

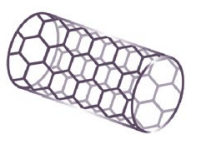

Carbon

Nanotube

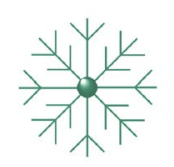

Dendrimer

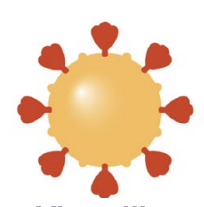

Virus-like Nanoparticles
Fig. 3 Schematic representation of the structural composition of different types of nanoparticles used for vaccine development
Despite these advantages, limitations of lipid-based nanoparticles include low encapsulation efficiency of hydrophobic molecules, poor biodistribution due to a high accumulation in the liver and spleen and, in rare cases, anaphylactic or severe allergy-like reactions as a response to high antibody levels induced by PEG [50, 52].

\subsection{Polymeric Nanoparticles}

Polymeric NPs can be fabricated with various types of natural materials such as chitosan, chondroitin, alginate, pectin, guar gum, dextran, and xanthan gum [42]. Similarly, synthetic polymeric materials such as polyacrylates, polycaprolactones (PCL), polylactic acid (PLA), poly (lactic-coglycolic acid) (PLGA), polylactide-polyglycolide copolymers, and charged polymers such as poly(amidoamine) (PAMAM) and poly(ethylenimine) (PEI) have been widely used for nanoparticle fabrication [42, 53]. Techniques for the synthesis of polymeric NPs such as emulsification, nanoprecipitation, ionic gelation, and microfluidics, allow precise control of multiple features including size, shape, charge, surface chemistry, and solubility [54]. Polymeric NPs enable different modalities for delivery: drugs, proteins, or genetic material can be conjugated to the polymer, encapsulated, immobilized into its matrix, or attached to the NP surface [54]. By fine-tunning properties such as composition and surface charge, the loading efficacies, release kinetics, and tissue-specific accumulation of these therapeutics are highly controlled [55].

Polymeric NPs are divided into two main categories, which include nanospheres (matrix systems) and nanocapsules (reservoir systems) [56]. These categories are further divided into micelles, polymersomes, and dendrimers. Polymeric micelles are nanostructures composed of amphiphilic block copolymers that self-assemble into a core shell structure in aqueous solutions [57]. Designing safe and effective micelles that exhibit multifunctional properties by integrating stimulisensitive groups and ligands for specific targeting has become especially relevant for the delivery of antibodies and small interfering RNA (siRNA) [57]. Polymersomes, self-assembled vesicles composed of amphiphilic polymers, offer several advantages over traditional liposomes in terms of structural stability; nevertheless, lipid/polymer hybrid vesicles allow a 
greater control and adaptability of physicochemical properties to any desired functionality or application [58]. Dendrimer NPs, composed of three-dimensional branched synthetic polymers that form interior and exterior layers ideal for molecular conjugation and encapsulation, have been employed in nanovaccination approaches for DNA or RNA delivery [59-61]. Polymeric NPs have been regarded as excellent candidates to deliver molecules due to their biodegradability, water solubility, biocompatibility, stability, and ability to perform targeted delivery. Some disadvantages, however, include risk of particle aggregation and toxicity [54].

\subsection{Inorganic Nanoparticles}

Inorganic-based platforms composed of metallic (e.g., gold and iron oxide), carbon-based (e.g., nanotubes), or semiconductor NPs (e.g., quantum dots) have been proposed as delivery vehicles for vaccination with promising results [62, 63]. Inorganic NPs exhibit unique size-dependent electrical, magnetic, and optical properties useful for immunological applications through targeting of multiple immune signals, enhanced stability, and delivery of otherwise insoluble cargo [64]. Simple surface modifications allow inorganic NPs to bind to antibodies, drugs, or other ligands and increase their biocompatibility [56]. Some common strategies followed for the fabrication of inorganic NPs include controlled crystallization (solvothermal synthesis or seeded growth), programmed assembly (thermodynamically driven), and templated assembly (coating, casting or breadboard) [65, 66].

Gold nanoparticles (AuNPs) are one of the most well-studied inorganic nanosystems due to their tunable properties and ease of functionalization $[67,68]$. Although limited, some inorganic materials such as iron oxide NPs (IONPs) have been FDAapproved for human use, while others are undergoing clinical trials $[69,70]$. Besides showing potential as delivery vehicles for antigens and adjuvants, carbon-based nanotubes (CNTs) have shown unique infrared light-responsive properties to induce systemic immune responses [64]. Quantum dots, luminescent nanocrystals with a typical size between $2-10 \mathrm{~nm}$, have been primarily used for in vitro and in vivo imaging applications, nevertheless, they have also shown potential as co-delivery vaccine agents [66, 71]. In general, inorganic NPs are well suited for theranostic applications and offer the advantage of being highly versatile in size, structure, and geometry [54]. Some concerns that arise in the scientific community from these nanomaterials are potential long-term toxicity and limited biodegradability [64].

\subsection{Virus-Like Nanoparticles}

Immunization strategies have achieved mimicking the conformation of viral structures to create VLNPs or purify viral proteins to synthesize NPs. VLNPs provide several vaccination advantages, including an enhanced uptake through native viral mechanisms and more efficient stimulation of the immune response [72-75]. These nanoparticle systems can serve as vaccination platforms to facilitate the delivery of functionalized or encapsulated adjuvants, antigens, and genetic material that expresses antigenic structures to immunize the organism against pathogens.

VLNP-based vaccines have received attention as they allow the incorporation of ligands, immunomodulators, and targeting moieties into their structure via genetic engineering strategies [76]. VLNPs also offer diverse bioinspired-structures based on human (e.g., Ebola virus, hepatitis B virus, and human immunodeficiency virus) or plant (e.g., Tobacco mosaic virus, Cucumber mosaic virus, Cowpea chlorotic mottle virus) viruses, and modifications include synthetic surface glycans that play a crucial role in modulating protein-receptor interactions, proinflammatory signaling pathways, and cytokine expression [77-82]. Compared to the delivery of live-attenuated or wholeinactivated virus vaccines, VLNPs do not carry the native viral genetic material and thus are safer and non-infectious [83]. As platforms for vaccine development, VLNPs offer the advantage to be highly scalable and adaptable, and some expression systems such as yeast and bacterial cells may greatly reduce their cost during production [76, 84]. Additionally, VLNPs may be designed as multivalent antigen structures, which could provide enhanced cellular uptake and superior immune activation [84, 85]. Despite the potential of VLNPs, some challenges include eliciting the formation of specific protective antibodies, improving the limited duration of immune responses, and effectively mimicking the complex life cycle of some pathogens [85].

\subsection{Clinical Development of Vaccines}

Several biotechnology companies, hospitals and universities created alliances across industrial and academic settings to rapidly advance basic and clinical research while developing nanovaccination systems during this pandemic (Table 1). For 
these vaccines to reach the general population, a rigorous clinical development and evaluation process has been followed. According to the WHO, a successful vaccine should reduce disease by at least $50 \%$ and show precise information to conclude that vaccine efficacy exceeds 30\% (95\% CI trial result should exclude lesser efficacies than 30\%) [86]. Evaluation from the FDA includes this lower limit of $30 \%$ as a criterion for vaccine approval. Part of these efforts resulted in the creation of two highly efficacious vaccines, BNT162b2 by Pfizer-BioNTech and mRNA-1273 by Moderna; both vaccines use nanotechnology as an essential part of their design to deliver mRNA [87].

Once a potential antigen of an infectious pathogen has been identified, the first step involves the development of the mRNA sequence that can express this antigen and its cellular and animal testing (pre-clinical stage) to determine its efficacy [88]. The second step consists of clinical trials, a sequential four-phase process in which the vaccine candidate is tested on humans [89]. During Phase I, small groups of people (hundreds) receive the trial vaccine to evaluate safety and immunogenicity. If satisfactory results are obtained, the vaccine candidate proceeds to Phase II with the objective to expand safety evaluation, identify the optimal dose, and study the efficacy in a larger population (25-1000 or several hundred volunteers) [90]. Phase III trials assess the efficacy of the vaccine in hundreds or thousands of participants, and if other vaccines for the same pathogen exist, a direct comparison is often performed [91].

If favorable results occur in these three phases, an application for registration and approval of a vaccine can be presented to regulatory agencies, such as the FDA in the case of the U.S., which in turn will evaluate the data and make a final decision as to whether it should be approved for clinical use [92]. As all potential short- and long-term adverse events cannot be anticipated until vaccine administration to the general population occurs and time has passed, a Phase IV clinical trial is often done after vaccine approval. This allows for monitoring the safety and efficacy of the vaccine in populations of 100,000 to millions [90]. The probability of success for a vaccine candidate varies by phase and therapeutic area, according to an analysis of Wong et al. that included vaccine candidates from 406,038 trials conducted from January 1, 2000, to October 31, 2015 [93]. The probability of successfully advancing vaccine candidates for infectious diseases to the next clinical phase is $76.8 \%$ for Phase I to II, 58.2\% from Phase II to III, and $85.4 \%$ for Phase
III to approval [93]. Approximately one third (33.4\%) of the candidates succeed clinical trial phases and reach the public based on this analysis [93].

Generally, vaccine development from conception to approval can take from years to decades. As an example, mumps, rotavirus, and varicella vaccines took four, fifteen, and twenty-eight years to reach the general population, respectively [94]. Nevertheless, because of this global crisis, vaccines against COVID-19 have been developed with unprecedented speed [95]. Each of these stages of pre-clinical and clinical development was speeded up and profuse amounts of investments from the private and public sector were provided to facilitate rapid progress. To accelerate the clinical testing process of a SARS-CoV-2 vaccine, several clinical phases ran in parallel, not sequentially, and in the U.S., Pfizer-BioNTech and Moderna were the first to be granted a fast-track designation by the FDA to expedite clinical studies and approval processes [96, 97]. The accelerated development of vaccines, combined with the novelty of the technologies adopted for their production may result on several concerns, including technical manufacturing problems and ethical matters regarding global access and availability of vaccines [98]. The unprecedented speed in the development of vaccines provides many lessons for the future such as insights on regulations, global access, clinical development, chemistry manufacturing and controls, and post-deployment monitoring [99].

\section{Differences Between DNA- and mRNA-Based Nanovaccines}

The use of nucleic acids is one of the strategies that biotechnology companies and academic institutions have implemented to generate vaccines against SARS-CoV-2. This vaccine type relies on the delivery of genetic information to cells, usually as plasmid deoxyribonucleic acid (pDNA) or mRNA, to encode antigens and induce an immune response in the organism [100,101]. While mRNA vaccines only need to cross the cellular membrane and reach the cytoplasm of a targeted cell to elicit an effect, pDNA vaccines need an additional step by crossing the nuclear envelope [102]. However, the delivery of unprotected pDNA or mRNA represents a challenge, as enzymatic degradation of the generic material and inefficacy crossing biological barriers such as cellular and 


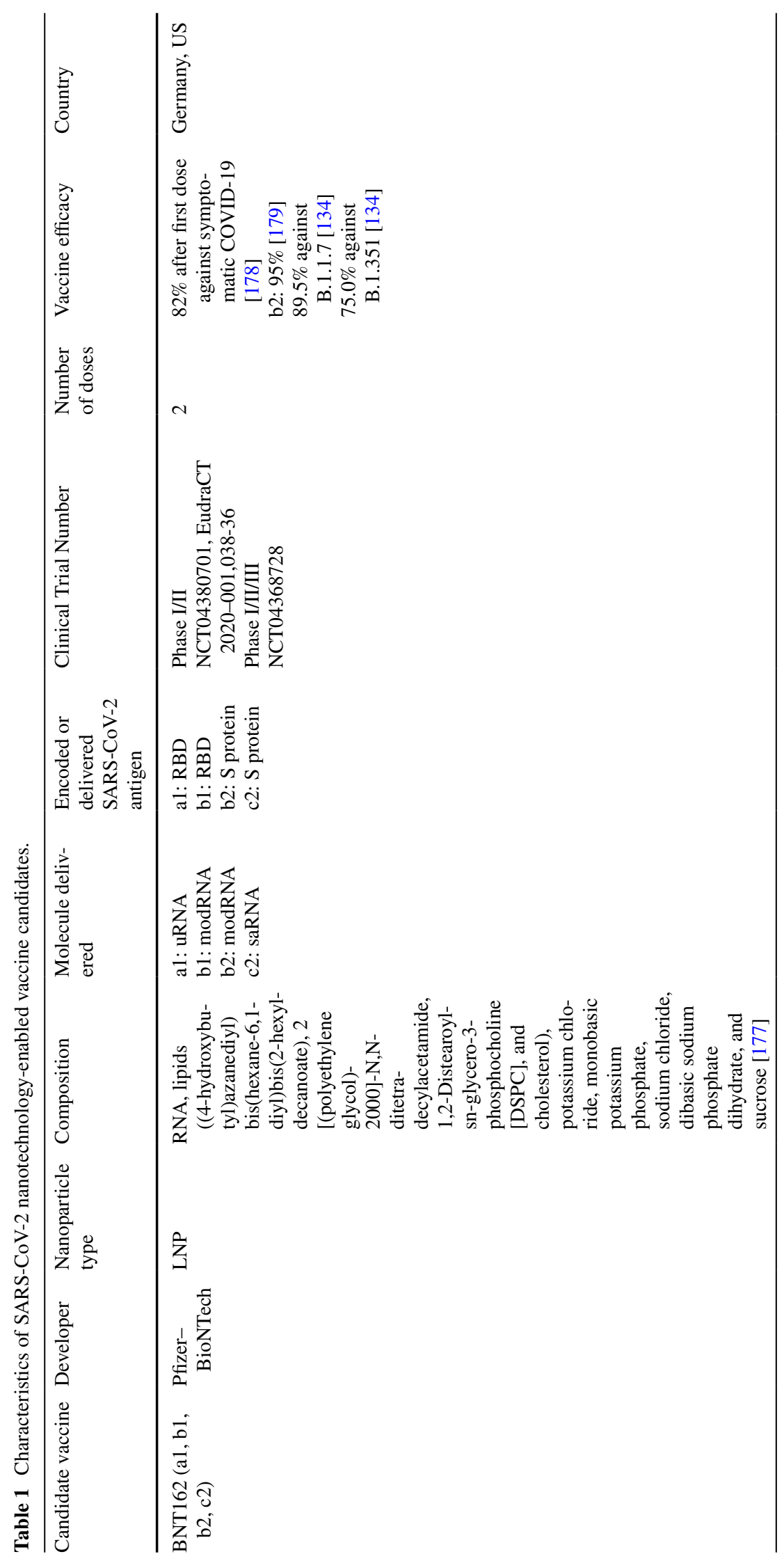




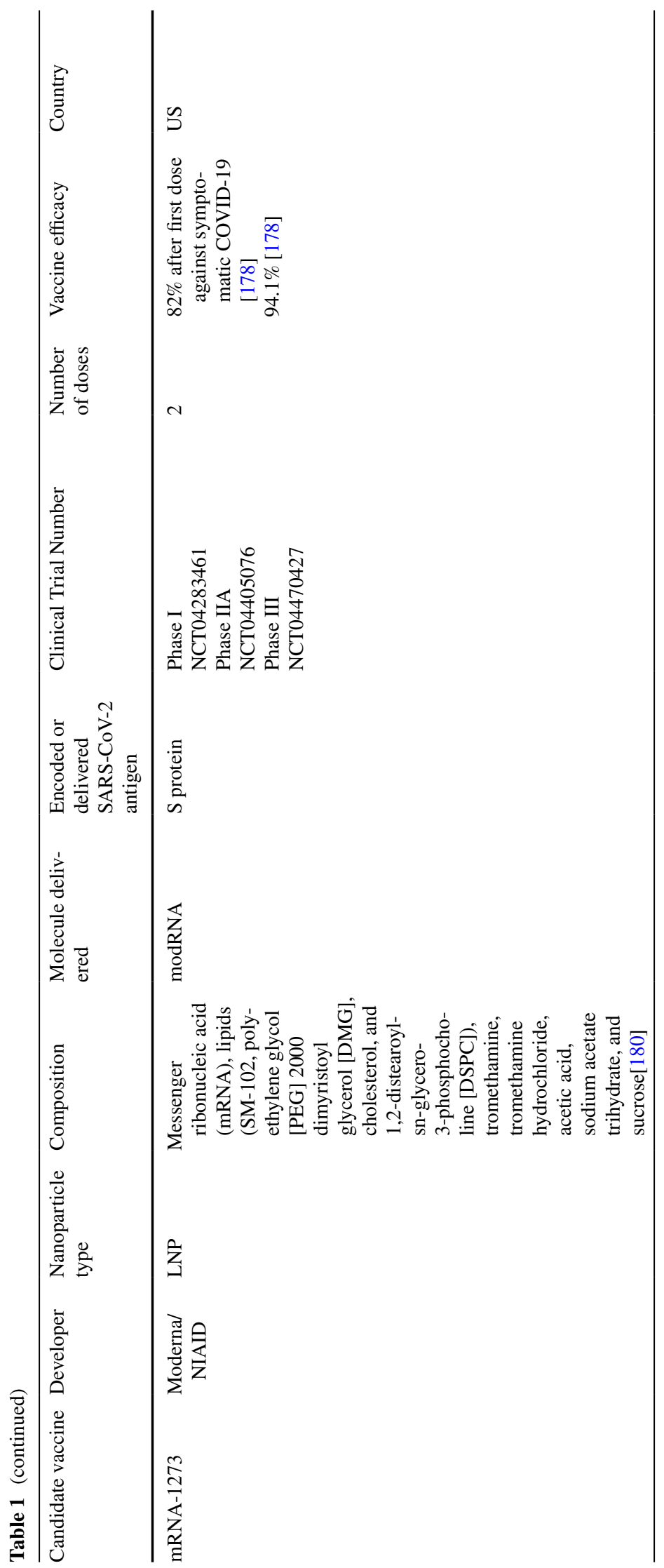

(in shanghai JiAO TONG UNIVERSITY PREsS 


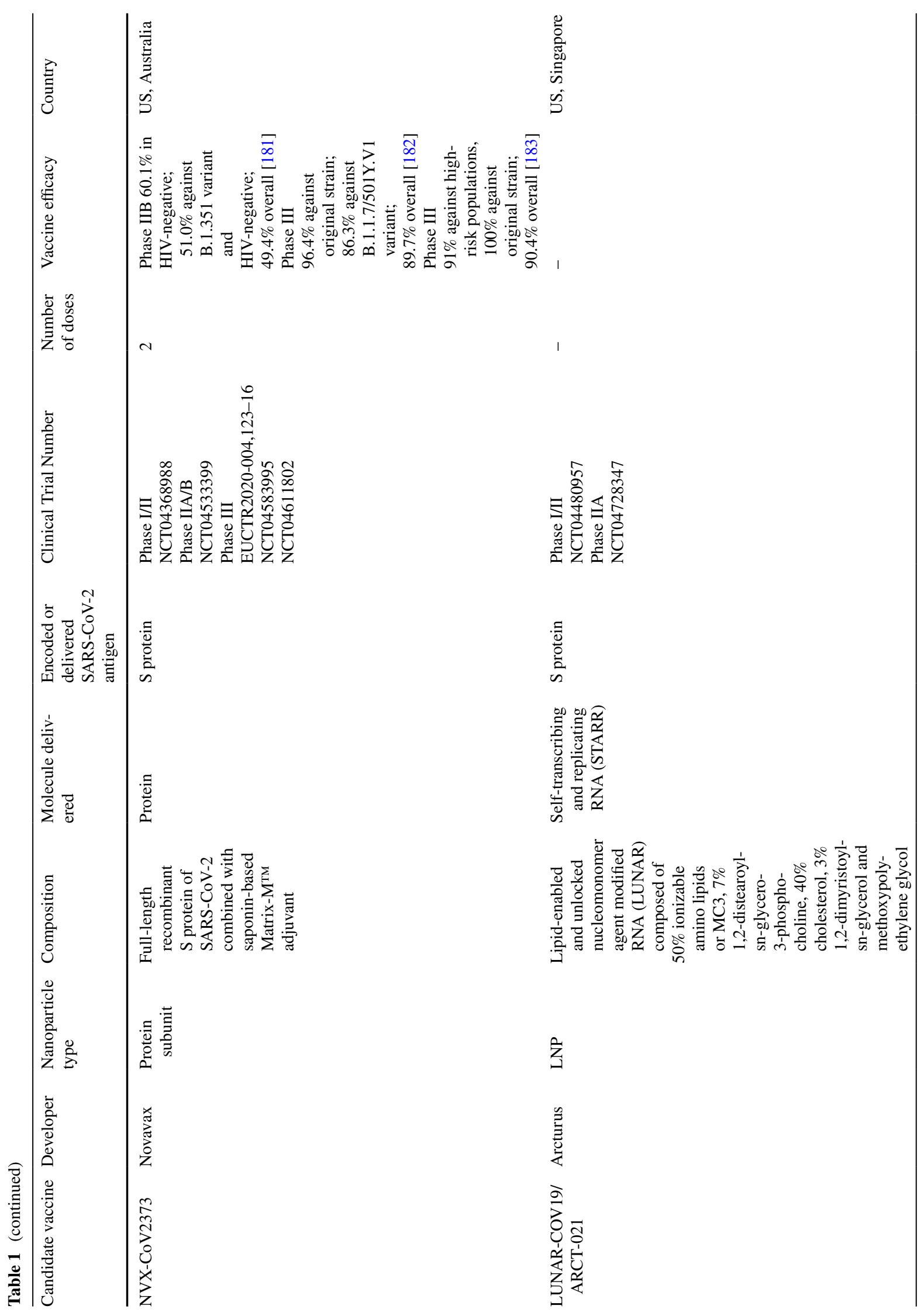




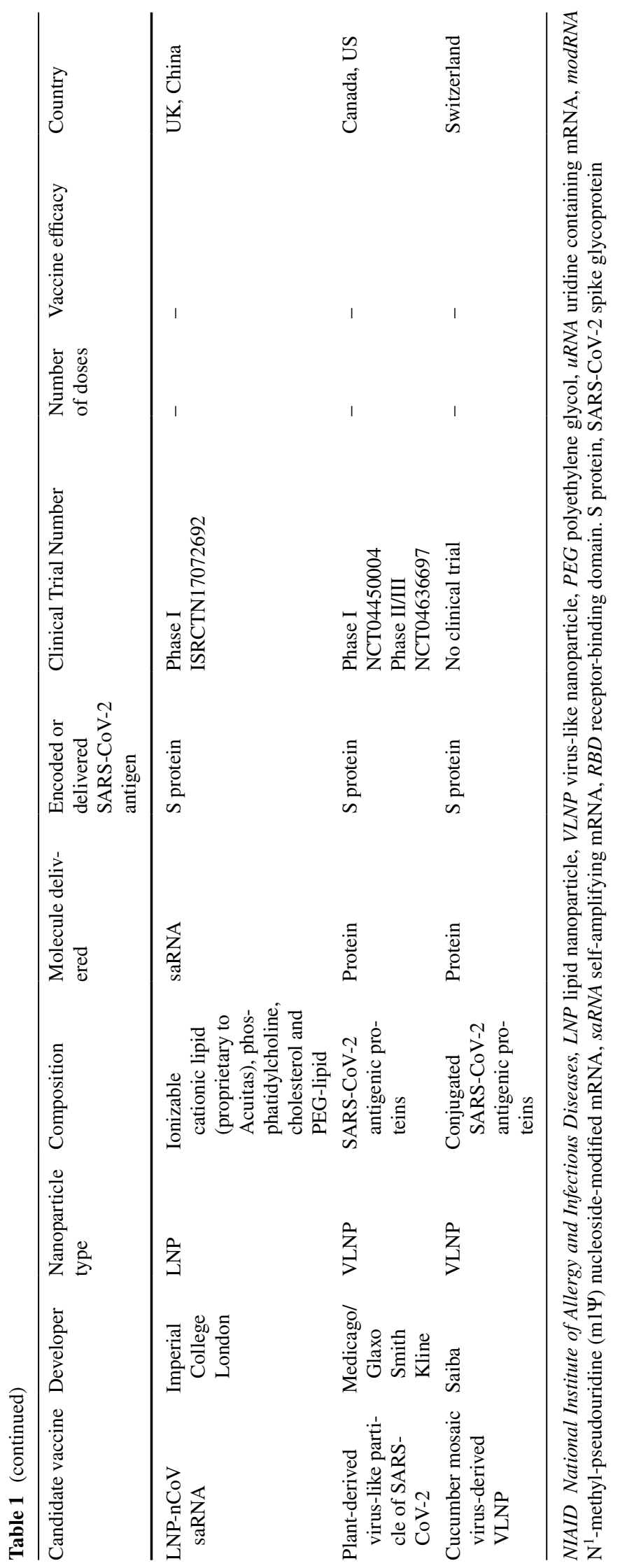


nuclear membranes normally occurs [103]. Nanoencapsulation of nucleic acids to produce vaccines has been established as an innovative approach to enable the delivery and protection of genetic material against possible extracellular degradation while preserving its programmed immunologic effect, and several of the nanoparticle-based vaccines against COVID-19 take advantage of this strategy [104, 105].

To fabricate nucleic acid nanovaccines, DNA or mRNA are typically mixed with cationic lipids or polymers to form an electrostatic complex that is subsequently encapsulated into a nanoparticle system [106]. The resulting nanocarrier prevents ribonuclease activity in the genetic construct and facilitates its cellular uptake by APCs via a cell membrane fusion mechanism in the case of most lipidbased systems or through endocytic and phagocytic pathways when polymer-based systems are used [106-109]. One advantage of using nanotechnology-based systems to deliver genetic material is that specialized transfection equipment, such as electroporation or gene guns, is not necessary [110].

During the internalization process of most lipid-based systems, when the nanoparticle shell integrates into the cell membrane, the genetic material is released directly into the cytoplasm (Fig. 4a) [111]. When hybrid lipidpolymer nanoparticles (LPNPs) with cationic components are taken up into the cell, a phagosome or endosome is formed around the particle and maturation into a phagoor endolysosome will result in its disruption via a $\mathrm{pH}$ dependent proton sponge effect releasing its content to the cytoplasm (Fig. 4b) [112]. In the case of pDNA-based nanovaccines, the genetic material is expected to reach the nucleus where transcription of mRNA molecules will take place, a more complex mechanism when compared to mRNA-based nanovaccines where the genetic cargo just needs to reach the cytoplasm to have an effect [113]. Both approaches result in ribosomal translation, production of antigenic proteins, proteasome activity, and subsequent extracellular presentation of the genetically encoded antigens $[114,115]$. After the migration of APCs to local lymph nodes, antigen presentation will trigger cytokine release, induction of cellular responses in $\mathrm{CD} 4^{+}$and $\mathrm{CD} 8^{+}$ $\mathrm{T}$ cells, activation of the adaptive immune system and humoral immunity by antibody-producing B cells [115].
Some advantages of using mRNA-based vaccines over their DNA counterparts include their null interaction with the host-cell DNA avoiding possible risks of genomic integration [110]; other benefits when mRNA-based vaccines are compared to viral-based platforms include the absence of anti-vector immunity as it contains an open reading frame encoding the selected antigen and specific regulatory elements which permits its administration multiple times [110].

\section{The Emergence of mRNA Nanovaccines During the COVID-19 Pandemic}

Before the emergency use authorization (EUA) of Pfizer-BioNTech's and Moderna's vaccines by the FDA, mRNA-based vaccines have never been FDA-approved in humans for any disease. In the past, however, DNA-based vaccines were already commercially available for veterinary uses such as the prevention of the West Nile Virus in horses and canine melanoma showing no safety concerns [116-118]. In addition, during 2016 and 2017, there were several ongoing human clinical trials evaluating the efficacy of mRNA-based vaccines against cancer and some infectious diseases, [101, 119-121]. Although mRNA technology has shown promising results on in vitro and in vivo models since 1990, there was no substantial investment in developing mRNA therapeutics, mainly because of concerns associated with mRNA instability, high innate immunogenicity, and inefficient in vivo delivery [101, 122]. Novel strategies, including the incorporation of pseudouridine and development of nanoparticle delivery platforms, were crucial for mRNA-based vaccines to emerge as attractive approaches with excellent biocompatibility profiles, facile scalability, and easy manufacturing [101, 123].

Efforts from several companies (Pfizer-BioNTech, Moderna and Arcturus) and academic institutions (Imperial College London) have been made for the development of effective nanotechnology-enabled mRNA vaccines, nevertheless, to date only Pfizer-BioNTech's and Moderna's mRNA vaccines have received emergency approval, and in the next sections of this review article, the preclinical and clinical development of these two SARS-CoV-2 vaccines will be described in detail. 


\section{(a) Mechanism of action of liposomal nanoparticles}

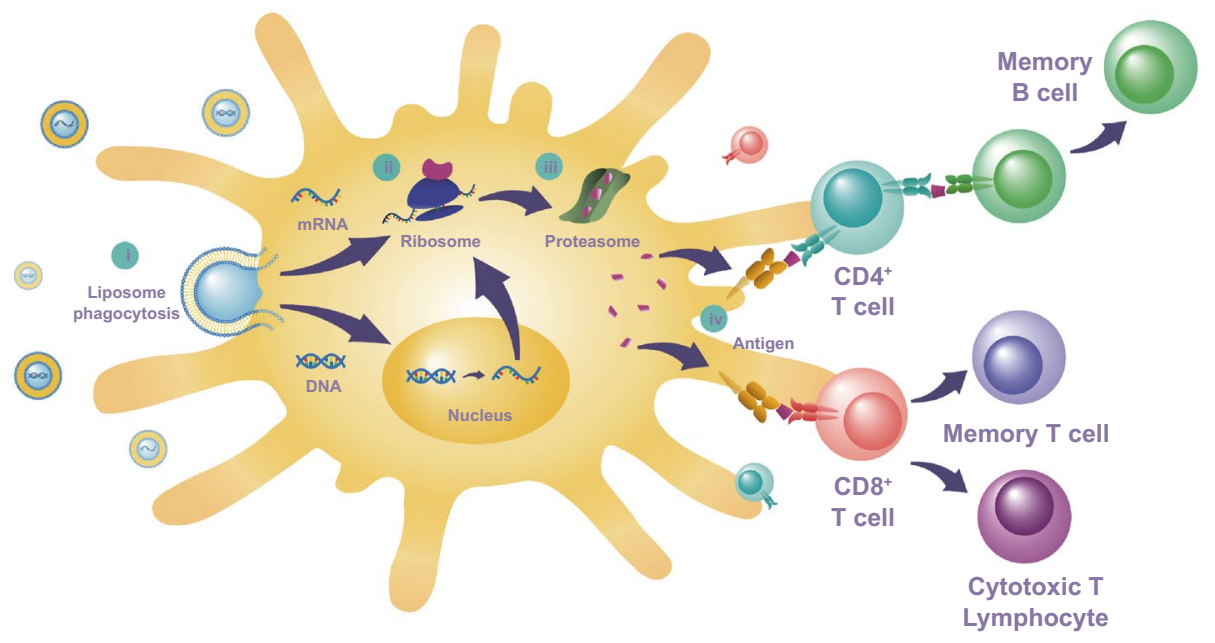

(b) Mechanism of action of lipid-polymer nanoparticles

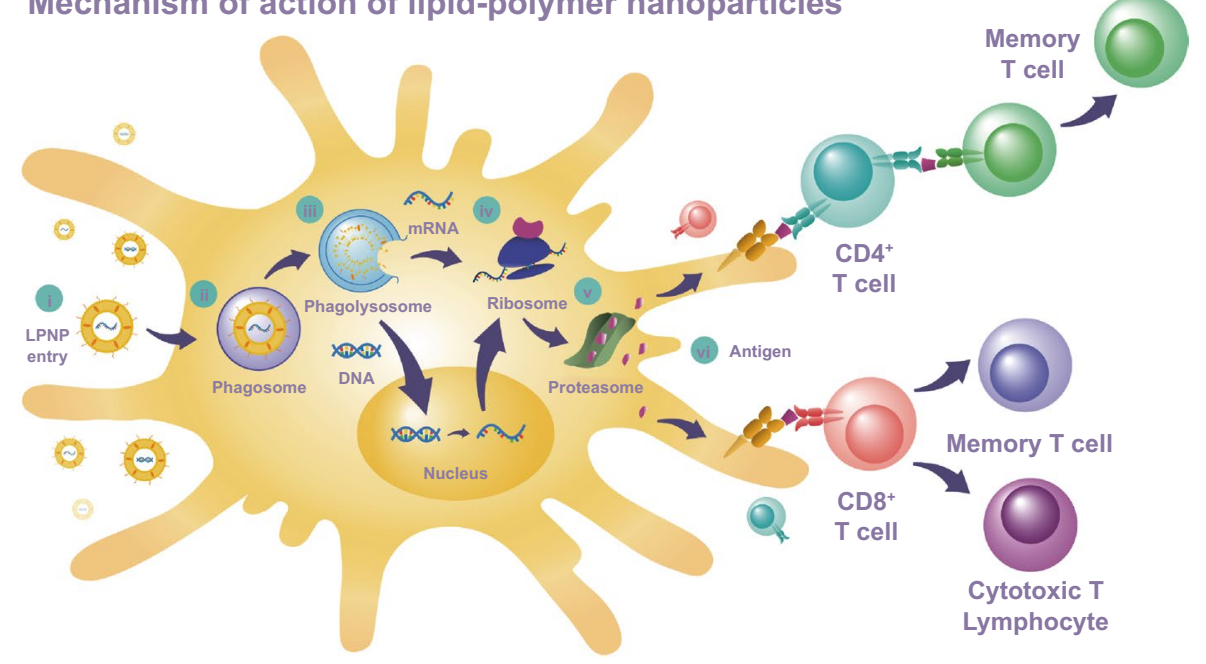

Fig. 4 Schematic representation of nucleic acid-based nanovaccination mechanism. a Liposomal nanoparticle vaccines (i) The liposomal nanoparticle reaches APC membrane and fuses. (ii) If the cargo is mRNA, it reaches the cytoplasm and is ready for translation. If the cargo is DNA, it must reach the nucleus for transcription into an mRNA molecule. (iii) Subsequently, ribosomes will translate the mRNA molecules into proteins. (iv) Proteasome activity will break the protein down in small antigenic fragments. (v) The antigenic fragments are presented on the APC membrane, and stimulation of the innate immune response is initiated by $\mathrm{CD}^{+}$and $\mathrm{CD} 8^{+} \mathrm{T}$ cells. b Lipid-polymer nanoparticle vaccines (i) lipid polymer nanoparticle (LPNP) reaches APC membrane. (ii) The LPNP is taken up by a phagosome or endosome. (iii) As the phagosome or endosome ages, a phago- or endo-lysosome is formed and later disrupted due to $\mathrm{pH}$ changes releasing the genetic material to the cytoplasm. If the cargo is mRNA, it reaches the cytoplasm and is ready for translation. If the cargo is DNA, it must reach the nucleus for transcription into an mRNA molecule. (iv) The ribosomal machinery begins translating the mRNA to produce a protein. (v) Proteasome activity causes the breakdown of the protein in small antigenic fragments. (vi) The antigenic fragments are presented on the APC membrane for stimulation of the innate immune system by $\mathrm{CD} 4^{+}$and $\mathrm{CD} 8^{+} \mathrm{T}$ cells

\subsection{Pfizer-BioNTech SARS-CoV-2 Vaccine}

BioNTech is a biotechnology company that collaborated with Pfizer and Fosun Pharma to test and develop a SARSCoV-2 vaccine. For this purpose, four nanoparticle-based mRNA vaccine candidates (BNT162a1, BNT162b1,
BNT162b2, and BNT162c2) were under investigation. Each candidate possessed a different mRNA format encapsulated in a LNP: two vaccines (BNT162b1 and BNT162b2) contained $\mathrm{N}^{1}$-methyl-pseudouridine $(\mathrm{m} 1 \Psi)$ nucleoside-modified mRNA (modRNA); one (BNT162a1) uridine containing mRNA (uRNA); and one (BNT162c2) self-amplifying 
mRNA (saRNA) [124]. Two of the vaccines had a genetic sequence that expressed the $\mathrm{S}$ protein (BNT162b2 and BNT162c2) and the other two expressed the RBD of the spike protein (BNT162a1 and BNT162b1) [125]. The 80-nm sized NPs were composed of ionizable cationic lipids, phosphatidylcholine, cholesterol, and polyethylene glycol [126].

\subsubsection{Preclinical Studies}

In parallel to Phase I/II clinical trials (NCT04380701), antigenicity and immunogenicity of BNT162b1 and BNT162b2 were confirmed in vivo in both murine and primate animal models [127]. First, preclinical studies were performed in BALB/c mice $(n=8)$ by administering 0.2 , 1 , or $5 \mu \mathrm{g}$ of the BNT162b1 or BNT162b2, or a buffer as control, using a single-dose regimen. Results showed a high dosedependent response of either RBD- or S1-specific binding antibodies after the single dose, which increased more steeply for BNT162b2. On day 28, the administration of $5 \mu \mathrm{g}$ of BNT162b1 was enough to elicit a high RBD-binding response [Geometric mean titer $(\mathrm{GMT})=752,680$ ], similar to that observed when BALB/c mice were immunized with $5 \mu \mathrm{g}$ of BNT162b2 (GMT $=434,560)$.

To determine the protective immunity of the nanovaccine, a neutralization assay using vesicular stomatitis virus (VSV)-based SARS-CoV-2 pseudovirus was tested in mouse serum [127]. On day 28 after injection, a steady increase of $50 \%$ pseudovirus-neutralization levels were observed after administering $5 \mu \mathrm{g}$ of either candidate vaccine (GMT $=1,056$ for BNT162b1; 296 for BNT162b2). On days 12 and 28 after BNT162b injections, enzymelinked immunospot assay (ELISpot) showed production of IFN- $\gamma$ by $\mathrm{CD}^{+}$and $\mathrm{CD}^{+}{ }^{+}$T cells and IL- 2 by $\mathrm{CD} 8^{+}$cells in murine splenic $\mathrm{T}$ cells. These results were confirmed by intracellular-cytokine-staining flow cytometry analysis after ex vivo restimulation with a full-length $\mathrm{S}$ peptide pool.

An additional immunogenic analysis was performed in re-stimulated splenocytes obtained on day 28 from BNT162b-immunized animals with a full-length $S$ peptide pool [127]. After stimulation, IFN- $\gamma$ and IL-2 secretion was increased in Type 1 helper T-cell (Th1) cells compared to other cytokines, and IL-4, IL-5, or IL-13 in Type 2 helper T-cell (Th2) cells were undetectable. Although similar CD4 ${ }^{+}$ and $\mathrm{CD}^{+} \mathrm{T}$ cell response patterns were observed for both vaccines, a stronger IFN $\gamma$-producing $\mathrm{CD}^{+} \mathrm{T}$ cell response was observed in mice inoculated with BNT162b2.

To investigate the principal compartments for $\mathrm{T}$ and $\mathrm{B}$ cell priming and evaluate systemic effects, the effects of the BNT162b vaccine on proliferation and dynamics of immune cells in draining lymph nodes, blood, and spleen were studied [127]. Twelve days after the administration of $5 \mu \mathrm{g}$ of either vaccine, an increase of plasma cells, class-switched $\mathrm{IgG}^{+}$and $\mathrm{IgG} 2 \mathrm{a}^{+} \mathrm{B}$ cells, and germinal-center $\mathrm{B}$ cells in draining lymph nodes were observed, as well as an increase of class-switched $\operatorname{IgG} 1^{+}$and germinal-center B cells in spleens of mice, compared to the control. Mice injected with either vaccine also showed an increased level of $\mathrm{CD} 8^{+}$ and $\mathrm{CD} 4^{+} \mathrm{T}$ cells in the draining lymph nodes, which were notable for $\mathrm{T}$ follicular helper ( $\mathrm{Tfh}$ ) cells. Although both vaccines induced higher levels of $\mathrm{Tfh}$ cells in the blood and spleen, only BNT162b2 induced an increase of circulating CD8 ${ }^{+} \mathrm{T}$ cells.

To further test the clinical potential, nonhuman primates were selected in the same study to evaluate the neutralizing response and protective ability of both BNT162b vaccine candidates [127]. Rhesus macaques ( $n=6$, male, $2-4$ years old) were administered with two intramuscular inoculations (at a 3-week interval) with 30 or $100 \mu \mathrm{g}$ of BNT162b1, BNT162b2 or saline control. Results showed detectable levels of RBD-specific binding IgG antibodies by day 14 after one dose and increased levels 7 days after the second dose. On day 28, RBD-binding IgG geometric mean concentrations (GMCs) for BNT162b1 were 20,962 units (U) $\mathrm{mL}^{-1}$ and $48,575 \mathrm{U} \mathrm{mL}^{-1}$ at $30-\mu \mathrm{g}$ and $100-\mu \mathrm{g}$ dose levels, and for BNT162b2 were 23,781 $\mathrm{U} \mathrm{mL}^{-1}$ and $26,170 \mathrm{U} \mathrm{mL}^{-1}$ at $30-\mu \mathrm{g}$ and $100-\mu \mathrm{g}$ dose levels, respectively. Compared to the GMCs of RBD-binding IgG of a panel of 38 SARSCoV-2-convalescent human sera $\left(602 \mathrm{U} \mathrm{mL}^{-1}\right)$, the GMCs of inoculated primates were higher after one or two doses.

Neutralizing activity was measured from sera collected 7 or 14 days after the second dose by a SARS-CoV-2 neutralization assay [127]. Results showed that animals administered with $30 \mu \mathrm{g}$ and $100 \mu \mathrm{g}$ BNT162b1 had a reciprocal 50\% inhibitory dilution ( ID $_{50}$ ) GMT of 768 and 1714, respectively, and those administered with $30 \mu \mathrm{g}$ and $100 \mu \mathrm{g}$ BNT162b2 had a ID $_{50}$ GMT of 962 and 1,689. To further investigate the antibody responses for viral inhibition, neutralization GMT of sera collected 21 or 35 days after the second dose from vaccinated animals was compared 
to neutralization GMT of human sera from COVID-19 convalescent patients. Results showed that GMT neutralization of macaque sera was substantially higher than that of human samples $(\mathrm{GMT}=94)$.

To determine the protective immunity of the BNT162b2 nanovaccine after one or two doses, ELISpot was employed to evaluate $\mathrm{CD}^{+}{ }^{+}$and $\mathrm{CD}^{+}{ }^{+}$T-cell cytokine specific responses for $\mathrm{S}$ protein [127]. Results showed strong IFN- $\gamma$ but low IL-4 responses after the second immunization, and cytokine staining confirmed $\mathrm{CD}^{+} \mathrm{T}$ cells secretion of IFN- $\gamma$ as well as $\mathrm{CD}^{+} \mathrm{T}$ cells secretion of high IFN- $\gamma$, IL-2 or TNF levels but low IL-4 levels, indicating a Th1biased response.

The protective efficacy of both vaccines was further evaluated, as macaques $(n=12)$ previously immunized with either $100 \mu \mathrm{g}$ BNT162b1 $(n=6)$ or BNT162b2 $(n=6)$, were exposed to a total dose of $1.05 \times 10^{6}$ plaque-forming unit (PFU) of the SARS-CoV-2 USAWA1/2020 strain by intratracheal and intranasal routes forty-one to fifty-five days after the second vaccine dosage was administered [127]. Additionally, control macaques $(n=9)$, previously immunized with saline, received the same viral challenge. Reverse-transcription quantitative polymerase chain reaction (RT-qPCR) analysis was performed in bronchoalveolar-lavage (BAL) fluid, and viral RNA was found in the control group on day 3 (7 of 9) and on day 6 (4 of 8 , with one indeterminant result) after challenge; nevertheless, viral RNA was found in BNT162b1-immunized macaques only on day 3 (2 of 6) and not detected in BNT162b2-immunized macaques at any of the time points. In addition, nasal, oropharyngeal and rectal swabs were collected, and results analyzed by RT-qPCR showed viral RNA in the control group on the day after challenge (4 of 9) and in BNT162b2-inoculated macaques (5 of $6)$, but not from BNT162b1-inoculated macaques. Subsequent nasal swabs showed a decrease of viral RNA detection in control macaques at each sampling time point, a single detection on day 6 from BNT162b1-inoculated macaques, and no detection of BNT162b2-inoculated macaques at any time point. Similar patterns were observed in oropharyngeal and rectal swabs, validating the previous results.

Analysis of the SARS-CoV-2 neutralizing titers on inoculated and control macaques showed values that ranged from 208 to 1185 (BNT162b1), 260 to 1004 (BNT162b2), and undetectable levels (saline) [127]. An increase of SARSCoV-2 neutralizing titers was observed in control macaques as a response to the viral challenge. Nevertheless, no increase was observed on inoculated macaques with either vaccine, confirming a suppression of SARS-CoV-2 infection. Histological examination was performed in the lungs of the animals, and results showed localized areas of inflammation that were observed among all groups, including the control. This led to the conclusion that the primate animal model was primarily to study SARS-CoV-2 infection rather than COVID-19 disease.

\subsubsection{Phase I/II Clinical Trials}

Using the pegylated lipid nanoparticle system and based on the preclinical results, a combined Phase I/II (NCT04380701), randomized, placebo-controlled, and observer-blinded clinical study among healthy adults was initiated to determine the effective dosage, safety, tolerability, and immunogenicity [128]. The vaccine was administered in a population aged 18 to 55 years old while people aged 65 to 85 years. Three different dose levels of BNT162a1, BNT162b1, and BNT162b2 vaccines following a Prime/Boost $(\mathrm{P} / \mathrm{B})$ regimen were under evaluation. In a separate cohort, the BNT162c2 vaccine was administered using a single dose (SD) regimen. The design of the BNT162b1 vaccine is based on the nanoencapsulation of modRNA encoding for RBD of a trimerized SARS-CoV-2 $S$ protein [129]. It has been previously shown that the addition of a trimerization "foldon" derived from bacteriophage T4 fibritin promotes the formation of trimers that allow the presentation of multiple sites for protein-protein interactions [130]. Thus, the genetic material that encodes the RBD antigens was designed with this modification to increase immunogenicity.

The clinical results from three groups of subjects between 18 to 55 years old that were intramuscularly inoculated with the BNT162b1 vaccine at escalating dose levels (10, 30, and $100 \mu \mathrm{g}$ ) and one placebo group were reported [129]. The first group $(n=12)$ received two injections of $10 \mu \mathrm{g}$ on day 1 and 21 ; the second group $(n=12)$ received two injections of $30 \mu \mathrm{g}$ on day 1 and 21 ; the third group $(n=12)$ received a single injection of $100 \mu \mathrm{g}$ on day 1 ; and the fourth group $(n=9)$ received two doses of placebo (control) at day 1 and 21 . Seven days after the first and second dose were administered, localized pain at the injection site was the most frequent reaction with mild to moderate severity in all the treatment groups, except for 1 patient who reported severe 
pain after the first administration of $100 \mu \mathrm{g}$. Other experienced symptoms included muscle and joint pain, fatigue, headaches, and chills. Fever was reported after the first and second administrations of BNT162b1, and in the case of the $100-\mu \mathrm{g}$ group $50 \%$ of patients presented side effects; based on this, researchers decided to not administer a second dosage of this dose range. In other groups, only $8.3 \%$ had fever which was self-limited after 1 day with no other serious adverse effects reported.

The concentrations of RBD-binding IgG and SARSCoV-2 neutralizing titers were evaluated before (day 0) and after the first dose was administered [129]. Similarly, titers were assessed again 7 and 14 days after the administration of the second dose. By day 21 after the first dose, GMCs of RBD-binding IgG of the three dosages $(10,30$ and $100 \mu \mathrm{g})$ were $534-1778 \mathrm{U} \mathrm{mL}^{-1}$, compared to $602 \mathrm{U} \mathrm{mL}^{-1}$ of the convalescent sera obtained from 38 subjects ( 18 to 83 years old) 14 days after a COVID-19 diagnosis was confirmed. By comparison, the recipients of the $10 \mu \mathrm{g}$ presented similar RBD-binding IgG GMC levels to those found in the convalescent sera obtained from COVID-19 patients, whereas the 30 and $100 \mu \mathrm{g}$ groups had significantly higher titer levels than those measured in the convalescent serum panel GMC.

Seven days after the second dose, the levels increased for 10 and $30 \mu \mathrm{g}$ dose groups (4813-27,872 $\mathrm{U} \mathrm{mL}^{-1}$ ) and highly elevated concentrations persisted until day 35 (5880-16,166 $\mathrm{U} \mathrm{mL}^{-1}$ ) [129]. These results represent $\mathrm{a} \sim 8.0$-fold to $\sim 50$-fold increase in the RBD-binding $\mathrm{IgG}$ GMCs compared to convalescent serum panel GMC. RBD binding antibody titers did not increase for the $100 \mu \mathrm{g}$ dose group beyond 21 days after the first vaccination. Twenty-one days after the first dose of BNT162b1 was administered in all the treatment groups, a modest increase in SARS-CoV-2 neutralizing GMTs was seen. Seven days after the second dose of 10 and $30 \mu \mathrm{g}$ was administered, 1.8-fold and 2.8fold higher serum neutralizing GMT levels were detected in comparison to the ones found in the convalescent serum panel from SARS-CoV-2 infected patients. No significant difference in immunogenicity was found between the 30 and $100 \mu \mathrm{g}$ groups, and the authors concluded that a dose range between 10-30 $\mu \mathrm{g}$ was well tolerated and produced significant neutralizing titers against SARS-CoV-2.

The antibody and T cell responses from the BNT162b1 vaccine were studied in a second non-randomized, openlabel Phase I/II (NCT04380701) clinical trial in a population of healthy adults aged 18 to 55 years old [131]. Results indicated that after the administration of two doses of 1 and $50 \mu \mathrm{g}$ of the vaccine, strong antibody, $\mathrm{CD} 4^{+}$and $\mathrm{CD} 8^{+} \mathrm{T}$ cell responses were observed. RBD-binding $\operatorname{IgG}$ concentrations were quantified, and superior levels were detected when compared to those found in the COVID-19 convalescent human serum panel. On day 43, neutralizing GMTs from SARS-CoV-2 serum presented an increase of 0.7 -fold for the $1 \mu \mathrm{g}$ dose group and 3.5-fold for the $50 \mu \mathrm{g}$ dose group in comparison to convalescent human serum. Th1 skewed T cell immune responses with RBD-specific $\mathrm{CD} 8^{+}$and $\mathrm{CD} 4^{+}$ $\mathrm{T}$ cell expansion were observed in most subjects and IFN- $\gamma$ production was detected in both immune cell types. These results indicate that the BNT162b1 vaccine elicits a protective response against SARS-CoV-2.

\subsubsection{Phase II/III Clinical Trials}

As the Phase I/II clinical trial showed promising results, Pfizer-BioNTech decided to subject BNT162b2 into evaluation in a combined Phase II/III (NCT04368728) human clinical trial $[125,132]$. BNT162b2, which nanoencapsulates modRNA encoding for SARS-CoV-2 full-length S protein, was initially administered at a $30-\mu \mathrm{g}$ dose level in a two-dose regimen. The study was estimated to involve 30,000 subjects from 18 to 85 years old, including 120 sites globally.

In December 2020, Phase II/III clinical trials results showed an overall $95 \%$ protection efficacy against COVID19 for the BNT162b2 vaccine [133]. This multinational, randomized, placebo-controlled, observer-blinded clinical trial consisted of a total of 43,548 volunteers ( $\geq 16$ years old) who were randomly assigned at 152 sites worldwide in a 1:1 ratio to receive either the intramuscular vaccine $(30 \mu \mathrm{g})$ or a placebo, in a two-dose regimen, administered 21 days apart. This study evaluated the efficacy, safety, and immunogenicity of the vaccine for the prevention of COVID-19 illness with onset at least 7 days after the second inoculation in participants who were healthy or had a stable chronic condition (HIV, hepatitis B or C virus infection) and had not previously been infected by SARS-CoV-2 or received an immunosuppressive therapy.

After screening, a total of 43,448 participants received in a 1:1 ratio either BNT162b2 or a placebo, and data were collected on October 9, 2020, from a total of 37,706 participants [133]. The mean age among participants was 52 years, $49 \%$ were female, $42 \%$ were older than 55 years, $35 \%$ were 
obese and $21 \%$ had at least one co-existing medical condition. The racial and ethnic proportions of participants were White (83\%), Black or African American (9\%) and Hispanic or Latinx (28\%).

In the primary analysis for the efficacy of the vaccine, onset cases with no evidence of existing or prior SARSCoV-2 infection were identified in 162 individuals, 7 days after the second dose in the placebo group, while only 8 onset cases were found in subjects that received the BNT162b2 vaccine, resulting in an efficacy of $95 \%$, in a 95\% CI of 90.3 to 97.6 [133]. These results met the prespecified success criteria, and greatly exceeded the minimum FDA criteria (primary efficacy $>30 \%$ ) for authorization. In the case of participants without evidence of SARS-CoV-2 infection, nine individuals exhibited symptoms of COVID19 at least 7 days after the second dose of the vaccine, and 169 individuals among placebo recipients $(94.6 \%$ vaccine efficacy). Severe cases of COVID-19 with onset at any time after the first and second inoculation were identified in 39 individuals of the vaccine group and 82 of the placebo group (52\% vaccine efficacy), indicating early protection that starts as soon as 12 days after the first dose.

Safety evaluations considered specific local or systemic reactogenicity and the use of pain medication within 7 days after each inoculation or placebo, and unsolicited adverse events through 1 month and through 6 months, both after the second dose (data through 14 weeks after the second dose is reported) [133]. The most common adverse reaction in participants 16 to 55 years old after the first dose or placebo was injection site pain ( $83 \%$ or $14 \%$ ), fatigue ( $47 \%$ or $33 \%$ ), and headache ( $42 \%$ or $34 \%$ ). In participants over 55 years old, adverse reactions after the first dose or placebo were injection site pain ( $71 \%$ or $9 \%$ ), fatigue (34\% or $23 \%$ ), and headache $(25 \%$ or $18 \%)$. Most side effects in both vaccine and placebo groups were mild to moderate and were less common in older vaccine groups.

Severe adverse events were identified in $0.6 \%$ of vaccine recipients and $0.5 \%$ of placebo recipients and both local and systematic reactogenicity resolved shortly after the injection [133]. Although other adverse events included shoulder injury, lymphadenopathy, paroxysmal ventricular arrhythmia, and right leg paresthesia, only a few participants were withdrawn because of serious adverse events. Death cases occurred in six participants during the trial, nevertheless, none of them were considered as consequences from either the vaccine or the placebo. Overall, reactogenicity events were transient and resolved within a couple of days after onset, and serious adverse events were minimal.

As it has been reported, current BNT162b2 efficacy against new SARS-CoV-2 variants could be compromised [135]. For that reason, the implementation of an updated vaccine boost is under clinical review.

\subsection{Moderna SARS-CoV-2 Vaccine}

Moderna is a biotechnology company based in Cambridge, Massachusetts, which has developed a vaccine candidate (mRNA-1273) by nanoencapsulating a modRNA sequence encoding the S protein of SARS-CoV-2 with 2 proline mutations substituted into residues 986 and 987 (SARS-CoV-2 S-2P) into LNPs [136]. The composition of the nanodelivery system includes ionizable lipids, distearoyl phosphatidylcholine, cholesterol, and polyethylene glycol (molar ratio: 50:10:38.5:1.5) and is fabricated using an ethanol nanoprecipitation method. The nanoparticle size of this vaccine is between $80-100 \mathrm{~nm}$ and possesses a mRNA encapsulation efficiency superior to $90 \%$.

\subsubsection{Preclinical Studies}

Prior to human clinical trials, the antigenicity and immunogenicity of this vaccine candidate were confirmed in vitro and in vivo in several murine strains [136]. Preclinical studies were performed in BALB/cJ, C57BL/6J, and B6C3F1/J mice by administering $0.01,0.1$, or $1 \mu \mathrm{g}$ of the mRNA- 1273 nanovaccine using a two-dosage regimen at a 3-week interval. Results showed a dose-dependent response of S-specific binding antibodies in all mice strains after the first (prime) and second (boost) dosages of the vaccine were administered. The administration of $1 \mu \mathrm{g}$ of mRNA-1273 was enough to elicit a potent neutralizing response, based on the reciprocal $\mathrm{IC}_{50}$ GMT results, similar to that observed when $\mathrm{BALB} / \mathrm{cJ}$ mice were immunized with $1 \mu \mathrm{g}$ of Sigma Adjuvant System (SAS)-adjuvanted S-2P protein. Based on these results, a wider dose range of mRNA-1273 $(0.0025-20 \mu \mathrm{g})$ was investigated in $\mathrm{BALB} / \mathrm{cJ}$ mice, and dose-dependent correlations between binding antibodies induced by mRNA1273 and neutralizing antibodies were observed. To further understand the potential clinical utility of a single-dose vaccination regimen, BALB/cJ mice were immunized with 1 or $10 \mu \mathrm{g}$ of the nanoencapsulated vaccine mRNA-1273. In 2 to 
4 weeks, the group administered with $10 \mu \mathrm{g}$ developed solid and increasing neutralizing antibody responses as determined by the reciprocal $\mathrm{IC}_{50}$ GMT. These data confirmed the efficacy of the SARS-CoV-2 S-2P mRNA nanovaccine to produce neutralizing antibodies with a single dose.

Th1 and Th2 responses were evaluated by comparing the levels of S protein-specific IgG2a/c and IgG1 between the nanovaccine group and a group administered with the SARSCoV-2 S-2P protein and the TLR4-agonist SAS [136]. The Th1/Th2 response observed was balanced in both groups, as S-binding antibodies, IgG2a and IgG1, were elicited by both immunogens. A single administration of mRNA-1273 resulted in a similar S-specific IgG subclass profile than the two-dose regimen. A different group was administered intramuscularly with the SARS-CoV-2 S protein in combination with $250 \mu \mathrm{g}$ of alum hydrogel resulting in lower response ratios of $\mathrm{IgG} 2 \mathrm{a} / \mathrm{IgG} 1$ subclass Th2-biased antibodies. Based on these results, the group concluded that the mRNA-1273 vaccine does not generate Th2-biased responses, which have been related to the vaccine-associated enhanced respiratory disease and observed in children vaccinated with wholeinactivated measles or respiratory syncytial viruses [137, 138].

An immunogenic analysis was performed in splenocytes obtained from mRNA-1273-immunized animals and re-stimulated with different peptide pools (S1 and S2) that correspond to the $\mathrm{S}$ protein of the virus [136]. After stimulation, IFN- $\gamma$ secretion was increased compared to other cytokines such as IL-4, IL-5, or IL-13, and the group stimulated with SARS-CoV-2 $\mathrm{S}$ protein combined with alum resulted in a skewed Th2 cytokine secretion. After 7 weeks, intracellular cytokine staining was used to measure the cytokine patterns induced by mRNA-1273 in memory T cells. A dominant Th1 response was found in $\mathrm{CD} 4+\mathrm{T}$ cells when higher immunogen doses were present; in the case of $\mathrm{CD} 8^{+} \mathrm{T}$ cells, a robust immune reaction to the $\mathrm{S} 1$ peptide pool with $1 \mu \mathrm{g}$ dose of mRNA-1273 was observed. These results indicate that mRNA nanovaccination is able to induce a balanced Th1/Th2 response, compared to the co-administered S protein and alum group where the Th2 response was dominant.

To determine the protective immunity of the nanovaccine, adult BALB/cJ mice were exposed to a mouseadapted (MA) SARS-CoV-2 that presents localized viral replication in the nasal airways and lungs [136]. Two doses of $1 \mu \mathrm{g}$ of mRNA-1273 were administered and it was determined that animals were fully protected, as viral replication was undetectable in the lungs after the challenge at 5- and 13-week intervals following a boost. Viral replication was undetectable in nasal turbinates on 6 out of 7 animals. For 0.01 or $0.1 \mu \mathrm{g}$ dose levels, a dosedependent efficacy was observed as the lung viral load was reduced $\sim 3$ - and $\sim 100$-fold, respectively. Animals that received the MA SARS-CoV-2 challenge at 7 weeks after one dose of 1 or $10 \mu \mathrm{g}$ of the nanovaccine was administered, were completely protected against MA SARS-CoV-2 replication in the lungs. These results confirmed the immunogenicity and efficacy of mRNA-1273 in a murine model and positioned this prototype as a robust candidate for SARS-CoV-2 vaccine.

In a second preclinical study, nonhuman primates were selected to test the neutralizing response and protective ability of this mRNA vaccine [139]. Rhesus macaques $(n=24$, 12 per sex) were divided into groups of three and administered with two intramuscular inoculations (at a 4-week interval) of 10 or $100 \mu \mathrm{g}$ of mRNA-1274 in $1 \mathrm{~mL}$ of $1 \mathrm{X}$ PBS depending on the group. An unvaccinated control group was administered with the same volume of PBS without mRNA.

Results showed a dose-dependent response of S-specific binding IgG antibodies after two vaccinations [139]. Neutralizing activity in animals that received $100 \mu \mathrm{g}$ of mRNA1273 had a $\mathrm{ID}_{50}$ GMT that was 5 and 18 times greater than the $10 \mu \mathrm{g}$ dose groups after the first and second vaccination. To further investigate the antibody responses for viral inhibition, serum from vaccinated animals was collected and compared to serum from COVID-19 convalescent human samples. Results analyzed by enzyme-linked immunosorbent assay (ELISA) showed that the binding inhibition of ACE2 to the RBD in serum from $100-\mu \mathrm{g}$ vaccinated animals was 938 and 348 times higher than that of the control animal group and human convalescent serum, respectively. Additionally, to assess the nanovaccine potential to recognize multiple functional $\mathrm{S}$ domains, additive neutralizing activity, post-attachment fusion inhibition, and binding of the NTD of S1 were evaluated. A higher S1 NTD-specific antibody response was elicited by the nanovaccine than the one observed in the human convalescent serum. Finally, the neutralizing activity was evaluated for 10 and $100 \mu \mathrm{g}$ vaccinated animals using a live SARS-CoV-2 reporter virus, resulting in an $\mathrm{ID}_{50}$ GMT 12 and 84 times higher, than the one observed on human convalescent sera.

To determine the protective immunity of the nanovaccine, flow cytometry was employed to evaluate the functional 
heterogeneity of $\mathrm{CD}^{+}{ }^{+}$and $\mathrm{CD} 8^{+} \mathrm{T}$-cell cytokine responses specific for S protein [139]. Due to previous observations of robust antibody responses in modRNA vaccines associated with $\mathrm{CD}^{+}{ }^{+} \mathrm{Tfh}$ cells, interleukin-21 was also measured. Results showed a dose-dependent relationship in increasing Th1, and interleukin-21-producing Tfh cellular responses, and low or undetectable $\mathrm{CD} 8^{+} \mathrm{T}$-cell and $\mathrm{Th} 2$ responses for both dose levels of the vaccine.

The protective efficacy of the vaccine was further evaluated as macaques were exposed to a total dose of $7.6 \times 10^{5}$ PFU of the SARS-CoV-2 USAWA1/2020 strain by intratracheal and intranasal routes four weeks after the second vaccine dosage was administered [139]. Polymerase chain reaction (PCR) analysis was performed in BAL fluid, and subgenomic RNA was found in all the groups at different times; nevertheless, lower levels were observed in the 10 and $100 \mu \mathrm{g}$ groups compared to the control group.

Post-challenge S- and N-specific IgG antibody levels in BAL fluid were measured to investigate the immune mechanism against viral replication in lungs, and a dose-dependent increase in S-specific IgG antibody levels was detected in vaccinated animals [139]. S-specific IgG responses were higher than $\operatorname{IgA}$ responses. No anamnestic response was observed, at 2 weeks post-challenge, humoral S- and N-specific IgG levels were stable in vaccinated animals, in comparison with the increased antibody levels observed in the control group. Histological examination was performed in the lungs of the animals, and the $10 \mu \mathrm{g}$ group presented mild inflammation without viral RNA. No substantial inflammatory response was found in the $100 \mu \mathrm{g}$ group as no viral RNA or antigens were detected. These results confirmed that no immunopathologic changes associated with the vaccine were present.

\subsubsection{Phase I/II Clinical Trials}

After obtaining promising preclinical results, a human Phase I (NCT04283461) open-label, dose-escalation clinical trial was initiated to evaluate the security and reactogenicity of mRNA-1273 in 45 healthy adults (18 to 55 years old) [140-142]. The participants were intramuscularly inoculated with 25,100 , and $250 \mu$ g of mRNA-1273 ( $n=15$ per group) in a prime-boost regimen 28 days apart. On days 29 and 57 after the first and second inoculation, anti-S-2P antibody GMT was measured by ELISA and results showed that when a higher mRNA-1273 dose was used, an increased antibody response was present. The GMT levels after the first inoculation were 40,227 for the $25 \mu \mathrm{g}$ group, 109,209 for the $100 \mu \mathrm{g}$ group and 213,526 for the $250 \mu \mathrm{g}$ group, and the GMT levels after the second inoculation were 299,751 for the $25 \mu \mathrm{g}$ group, 782,719 for the $100 \mu \mathrm{g}$ group, and 1,192,154 for the $250 \mu$ group.

Serum neutralizing activity was measured by both pseudo-typed lentivirus reporter single-round-of-infection neutralization assay (PsVNA) and live wild-type SARSCoV-2 plaque-reduction neutralization testing (PRNT) assay. PsVNA responses were identified in half of the participants after the first vaccination, and in all the participants after the second vaccination [142]. The geometric mean $\mathrm{ID}_{50}$ levels at day 43 were 112.3 for the $25 \mu \mathrm{g}$ group, 343.8 for the $100 \mu$ g group, and 332.2 for the $250 \mu$ g group, similar to those found above the median values for human convalescent serum specimens in the distribution. In parallel at day 43, all participants developed a wild-type virus-neutralizing activity that was able to reduce SARS-CoV-2 infectivity by $80 \%$ or more $\left(\mathrm{PRNT}_{80}\right.$ ) (geometric mean of 339.7 for the $25 \mu \mathrm{g}$ group and 654.3 for the $100 \mu \mathrm{g}$ group). These responses were higher than the values of three convalescent serum specimens tested. When stimulated by S-specific peptide pools, the 25 and $100 \mu \mathrm{g}$ groups induced $\mathrm{CD}^{+} \mathrm{T}$ cell responses in line with Th1 cytokines (TNF- $\alpha$, IL-2 and IFN$\gamma$ ). Th2 cytokine expression (IL-4 and IL-13) was minimal in these 2 groups. Adverse events such as localized pain at the injection site, nausea, arthralgia, fatigue, chills, headache, myalgia, erythema, and induration were observed in a mild and moderate manner after vaccine administration. However, after the first vaccination, the vaccine was considered safe with mild-to-moderate adverse systemic events in 33\%, 67\%, and $53 \%$ of the 25,100 , and $250 \mu$ groups, respectively; after the administration of a second dose, mild-to-moderate adverse systemic events were observed in $54 \%, 100 \%$, and $100 \%$ of the participants in the 25,100 , and $250 \mu \mathrm{g}$ groups. Severe adverse events were found in three participants (21\%) from the high dose $(250 \mu \mathrm{g})$ group. Fever was present after the second vaccination in $0 \%, 40 \%$, and $57 \%$ of the 25,100 , and $250 \mu \mathrm{g}$ groups, respectively. It was concluded from these results that the mRNA-1273 vaccine was safe and able to generate immunogenic responses.

On 29 May 2020, a Phase II (NCT04405076) clinical randomized, observer-blinded, placebo-controlled study was conducted to evaluate the safety and immunogenicity 
of mRNA-1273 in 600 healthy adults $(\geq 18-<55, n=300$; and $\geq 55$ years old, $n=300$ ) [143, 144]. Participants were randomly chosen from either group to receive intramuscular inoculations with either 50 or $100 \mu \mathrm{g}$ of mRNA-1273 or a placebo in a two-dose regime, 28 days apart. Anti-SARSCoV-2-spike antibody GMT was measured by ELISA on days 1 and 29 after the first inoculation, and days 43 and 57 after the second inoculation. Results showed that 14 days following the second vaccination (day 43), antibodies were significantly enhanced to maximum GMTs and exceeded those of convalescent sera, remaining elevated through day 57. On day 43, GMT levels (95\% CI) were 1733 and $1909 \mu \mathrm{g} \mathrm{mL}^{-1}$ at $50 \mu \mathrm{g}$ and $100 \mu \mathrm{g}$ mRNA-1273 in younger adults; and 1827 and $1686 \mu \mathrm{g} \mathrm{mL}^{-1}$ at $50 \mu \mathrm{g}$ and $100 \mu \mathrm{g}$ mRNA-1273, in older adults [144].

The most common adverse events were localized pain at injection site, headache, and fatigue following each vaccination in both age cohorts [144]. Local and systemic adverse reactions were mostly mild-to-moderate in severity, at higher frequencies after the second dose, and one serious adverse event that occurred 33 days post-vaccination was concluded unrelated. These observations were consistent with previous reports on Phase I clinical studies. After these results, it was concluded that mRNA-1273 vaccine was safe and able to generate immunogenic responses.

On December 18, 2020, Moderna received investigational new drug approval from the FDA, and the initial placebo-controlled, dose-confirmation Phase I clinical trial was expanded to include older adults (56 to 70 years old $/ \geq 71$ years, $n=40$ ) [145]. This study evaluated the safety, reactogenicity, and immunogenicity of a prime-boost regimen of 2 dosages ( $25 \mu \mathrm{g}, n=10$ per age group; or $100 \mu \mathrm{g}$, $n=10$ per age group) of the mRNA-1273 vaccine, administered 28 days apart.

On days 29 and 57 after the first and second inoculation, anti-S-2P antibody GMT was measured by ELISA and results showed that at higher mRNA-1273 doses, antibody responses increased [145]. GMT levels after the second inoculation in the $25 \mu \mathrm{g}$ group were 323,945 for adults whose age ranged between 56 to 70 years old and 1,128,391 among older adults ( $\geq 71$ years). In the $100 \mu \mathrm{g}$ group, GMT levels after the second inoculation were far superior to those observed in convalescent sera $(\mathrm{GMT}=138,901)$ : $1,183,066$ among participants of the $56-70$ years old group and $3,638,522$ that were 71 years or older.
Serum neutralizing activity was measured by SARSCoV-2 native spike-pseudotyped lentivirus reporter singleround-of-infection neutralization assay (pseudovirus neutralization assay) against the original virus containing the aspartic acid (D) residue at position 614 [145]. The neutralizing activity of the vaccine against the polymorphic variant 614 glycine $(614 \mathrm{G})$ was evaluated with a second pseudovirus neutralization assay on day 43 . Additionally, three live-virus neutralization assays were used according to the age and dose subgroup: SARS-CoV-2 nanoluciferase highthroughput neutralization assay (nLuc HTNA) on days 1, 29, and 43 ( $\geq 56$ years, $100-\mu \mathrm{g}$ dose), a focus reduction neutralization test mNeonGreen (FRNT-mNG) on days 1, 29, and 43 (two age and dose subgroups) and a SARS-CoV-2 PRNT assay (days 1 and 43; two age subgroups, 100- $\mu$ g dose only).

Pseudovirus neutralization assay responses were identified 7 days after the second dose in participants independently of their age [145]. At day 43, the geometric mean $\mathrm{ID}_{50}$ titers to $614 \mathrm{D}$ induced by the $100 \mu \mathrm{g}$ dose level were $402 \mathrm{among}$ adults between ages 56-70 years, similar to 317 observed in adults that were 71 years of age or older. Responses among the $100 \mu \mathrm{g}$ subgroups were higher than those observed in the $25 \mu \mathrm{g}$ subgroups and above values in human convalescent serum. On day 43, strong neutralization responses were observed in all participants by nLuc HTNA, similar to those detected by FRNT-mNG. In parallel, on day 43, PRNT $_{80}$ geometric mean levels were 878 among adults between ages 56 and 70 years, and 317 among adults 71 years of age or older. All neutralization assays, nLuc HTNA, FRNT-mNG, and PRNT, correlated well, except results from PRNT and ELISA.

When stimulated by S-specific peptide pools, participants (56-70 years old) that received $25-\mu \mathrm{g}$ and $100-\mu \mathrm{g}$ (56 to 70 and $\geq 71$ years), induced $\mathrm{CD} 4^{+} \mathrm{T}$ cell responses in line with Th1 cytokines (TNF- $\alpha$, IL-2 and IFN- $\gamma$ ) [145]. Th2 cytokine expression (IL-4 and IL-13) was minimal in these 2 groups, similar results to those observed in the Phase I trial. Dose-dependent adverse events such as localized pain at the injection site, fatigue, chills, headache, myalgia, were observed in a mild and moderate manner after vaccination. However, after the first inoculation, the vaccine was considered safe with mild adverse systemic events in $30 \%$ of the 25 and $100 \mu$ g groups (56-70 years), and 50\% and 30\% of the 25 and $100 \mu$ groups ( $\geq 71$ years), respectively; after the second vaccination, mild-to-moderate adverse systemic 
severe events were observed in $70 \%$ and $88.9 \%$ of the 25 and $100 \mu \mathrm{g}$ groups (56-70 years), and $30 \%$ and $70 \%$ of the 25 and $100 \mu$ groups ( $\geq 71$ years), respectively. Severe adverse events were found in only two cases: fatigue in one participant $(10 \%)$ who was 71 years of age or older in the $100-\mu \mathrm{g}$ dose subgroup, and fever in one participant (10\%) between 56 to 70 years old from the $25 \mu \mathrm{g}$ subgroup after the second vaccination. In addition to Phase II results, it was concluded from this study that the $100-\mu \mathrm{g}$ dose of mRNA-1273 vaccine was safe, able to generate immunogenic responses and could further proceed for Phase III clinical trials.

\subsubsection{Phase III Clinical Trials}

In late July 2020, the Coronavirus Efficacy (COVE) Phase III clinical trial (NCT04470427) was initiated to evaluate the mRNA-1273 vaccine in preventing SARS infection. Early results from this randomized, stratified, placebo-controlled, observer-blinded Phase III clinical trial, conducted at 99 centers across the USA, were available in February 2021 [146].

The COVE Phase III clinical trial enrolled 30,420 volunteers who were randomly assigned in a 1:1 ratio to receive either the intramuscular vaccine $(100 \mu \mathrm{g})$ or a placebo, in a two-dose regimen, administrated 28 days apart [146]. This study evaluated the efficacy, safety, and immunogenicity of the vaccine for the prevention of COVID-19 illness with onset at least 14 days after the second inoculation in participants who had not previously been infected by SARSCoV-2. The mean age among participants was 51.4 years, $47.3 \%$ were female, $24.8 \%$ were older than 65 years, and $16.7 \%$ were under the age of 65 and had high-risk chronic diseases that increased the probability to develop severe COVID-19, such as diabetes, severe obesity, or cardiac disease. The racial and ethnic proportions of participants were White (79.2\%), Black or African American (10.2\%), and Hispanic or Latinx (20.5\%).

The efficacy of the vaccine was evaluated according to the protocol mRNA-1273-P301 based on the most recent clinical study protocol (CSP) Amendment 3 [146]. Immunogenicity analyses included serum binding antibody levels against SARS-CoV-2 as measured by ELISA specific to the SARS-CoV-2 S protein and tests such as VAC58 Spike
IgM Antibody, VAC58 Spike IgA Antibody, and VAC65 Spike IgG antibody. Additionally, serum neutralizing antibody titers against SARS-CoV-2 as measured by pseudovirus and/or live virus neutralization assays were performed, including tests such as PsVNT50 PsVNT80, and MN50 (live virus neutralization assay). In the primary analysis for the efficacy of the vaccine, 11 symptomatic COVID-19 participants were identified in the vaccine group and 185 in the placebo group. Secondary efficacy analysis of the vaccine included the identification of severe COVID-19 symptoms among participants. In the placebo group, 30 participants developed severe COVID-19 disease while no cases were observed in the vaccine group. The vaccine showed a $94.1 \%$ efficacy, which was similar to secondary analyses, including subjects who had evidence of infection at baseline and analyses of participants 65 years of age or older. Reactogenicity after vaccination was observed to be transient and moderate, which occurred more often in the mRNA-1273 group.

Safety evaluations considered participants' adverse events (solicited) after the first inoculation, as well as unexpected adverse events (unsolicited), after the second administration [146]. The most common adverse reaction after the two-dose series was injection site pain (84.2\%) and systemic adverse events after the first and second dose occurred more often in the vaccine group (54.9\% and 79.4\%) than in the placebo (42.2\% and $36.5 \%$ ) group after the first dose and the second dose, respectively; the most common unsolicited events included headache (1.5\% vaccine group, $1.2 \%$ placebo) and fatigue (1.4\% vaccine group, $0.9 \%$ placebo). While many of these adverse events were mild (grade 1) or moderate (grade 2), there was a higher occurrence of severe (grade 3) reactions in the vaccine group after the first $(2.9 \%)$ and second (15.8\%) inoculations. Most local adverse events occurred within the first one to two days after injection and generally persisted for a median of one to two days.

The adaptability of mRNA-based vaccines allows the manufacturing of specific nanovaccines against new SARSCoV-2 variants. For that reason, Moderna will conduct further clinical studies to evaluate mRNA-1273.351 against the variant B.1.351, as well as continue to evaluate a third vaccine boost of mRNA-1273 to determine its efficacy against other new variants that have emerged around the world [147]. 


\section{Nanoparticle-Based Vaccines to Deliver Nucleic Acids}

As discussed above, Pfizer-BioNTech's and Moderna's vaccines were the first vaccines that received emergency authorization by the FDA. For the development of their respective vaccines, Pfizer-BioNTech and Moderna used mRNA that encodes genetic variants of the SARS-CoV-2 spike protein that are more stable and immunogenic than the natural protein. To further increase the efficacy of the formulation, both vaccines use LNPs to encapsulate mRNA molecules to provide them with stability and protection. Advantages offered by this nanosystem include the use of biodegradable lipids, improving safety and tolerability. Other features include the incorporation of multifunctional lipids that act as adjuvants to boost vaccine efficacy [148]. Although immunogenicity of mRNA might represent a safety concern, Pfizer-BioNTech's and Moderna's vaccines include chemical modifications to nucleotides ( $\mathrm{N}^{1}$-methyl-pseudouridine) which reduce mRNA instability and innate immune responses from exogenous mRNA translation [148, 149].

Protein-based vaccines offer different advantages as the protein subunits are readily processed into antigens by APCs, avoiding the need for intracellular transcription. However, exposed antigens are subjected to enzymatic degradation before being recognized by immune cells, which impacts negatively on the vaccine effectiveness and multiple boost doses are usually required. By including adjuvants, however, this intrinsic disadvantage of peptide-based vaccines is countered, allowing the induction of higher immune responses [150].

When comparing mRNA and peptide-based vaccines, one key difference relies on the higher adaptability of mRNA platforms to emergent virus variants or future pandemics. A main concern of genetic vaccines is their safety profile; nevertheless, mRNA vaccines have proven to be not infectious and cannot potentially be integrated into the host genome [151]. Another difference is the storage conditions for each type of vaccine. Protein-based vaccines are stable at temperatures that range 2 to $8^{\circ} \mathrm{C}$ and Moderna's and Pfizer-BioNTech's mRNA vaccines require temperatures of $-20^{\circ} \mathrm{C}$ and -60 to $-80^{\circ} \mathrm{C}$ to remain stable for 6 months, respectively. Although it has been possible to store mRNA vaccines at 2 to $8{ }^{\circ} \mathrm{C}$ for 30 days, these conditions still represent a significant challenge for an equitable vaccine distribution to many developing countries $[101,152]$. As third doses and seasonal vaccine boosters may become necessary, worldwide efforts continue to ensure health and safety, including the approval of children's vaccination [153-155].

\section{Health and Economic Impact}

Around the world, biotechnology companies and academic institutions accelerated the development of nanotechnologyenabled vaccines with the aim of solving the existent health and economic crisis.

It is imperative to accelerate the manufacturing and distribution of vaccines in a sustainable and equitable manner to rapidly decrease the economic and health impact caused by this pandemic, especially among the most vulnerable and health professionals. A significant difference between mRNA vaccines is the dosage required: Moderna's vaccine requires $100 \mu \mathrm{g}$ whereas Pfizer-BioNTech's vaccine requieres $30 \mu \mathrm{g}$. Higher dosages also represent a limitation regarding mass production. In terms of efficacy against the original SARS-CoV-2, Pfizer-BioNTech possess the highest (95\%), following by Moderna (94.1\%).

In a globalized world, lack of vaccine supply for lowincome countries, which are the ones that would likely suffer from limited access, would not only affect public health, but also would take a substantial toll on the global economy. Further consequences would be related to a poor and slow stabilization in the productivity and economy of the world-wide population as the World Bank estimated a $5.3 \%$ contraction of the global gross domestic product (GDP) in 2020 [156]. All these effects are aggravated as a significant percentage of patients recovered from COVID19 will end up with a potential disability due to organic damage, as early evidence has shown that $75.4 \%$ of the survivors present abnormalities in lung function [157]. Additionally, 50\% of intensive care unit (ICU) patients will experience post-intensive care syndrome (PICS) that includes post-traumatic stress disorder, anxiety, depression, fatigue, insomnia, decreased memory, poor concentration and difficulty talking, and these factors contribute to a loss of economic productivity [158]. Thus, innovation and equitable manufacturing and distribution of effective vaccines will prevent new infections and significantly spur the economic outlook and recovery of societies around the 
world. Most vaccines developed or under development are based on injectable solutions. In the near future, inhalable vaccines could be created for self-administration without medical assistance, facilitating their distribution and benefiting people worldwide especially those with less developed or limited medical access $[159,160]$.

Even if vaccines are available, social distancing, use of face covering, and personal hygiene is recommended to control the spread of the pandemic in non-vaccinated populations [161, 162]. Planning security protocols for diverse industrial sectors will also be pivotal to lessen adverse consequences and prevent new outbreaks [163]. In addition, it is crucial to consider the continued emergence of SARS-CoV-2 lineages and their impact on vaccine efficacy. As an example, the lineage B.1.1.7 has been associated with a higher viral load and a reduced neutralization by RBD-specific and NTD-specific neutralizing antibodies (16\% and $90 \%$, respectively) $[164,165]$. In the case of lineage B.1.351, concurrent mutations have been hypothesized to overcome the polyclonal antibody response due to the significant reduction of neutralizing activity in sera collected from patients recovered from COVID-19 [26, 166]. Besides the effects of mutations on antibody binding and neutralization activity, the biological impact of mutated SARS-CoV-2 variants on T cell reactivity has also been investigated [167]. Tarke et al. directly compared SARS-CoV-2-specific CD4 ${ }^{+}$and $\mathrm{CD} 8^{+} \mathrm{T}$ cell responses of COVID-19 convalescent patients previously infected by B.1.1.7, B.1.351, P.1, and CAL.20C (B.1.427/B.1.429) viral lineages, and that were recipients of either mRNA1273 or BNT162b2 vaccines [168]. Results showed a decrease of $10-22 \%$ of the total reactivity, in terms of magnitude and frequency of response, against some VOC combinations. As new variants continue to emerge, information from previous mutations will help to predict altered antigenicity or transmissibility of new viral lineages [169].

Given the urgent need to increase the production and distribution efforts of vaccines against COVID-19, monetary support to scientific and industrial infrastructure is of uppermost importance. These efforts will decrease mortality and disability around the world, and increase the productivity rates across the nations, having permanent long-term economic and health benefits. Monitoring and evaluating longterm adverse effects associated with current mRNA vaccines will also be crucial; however, current clinical evidence supports their short- and long-term biosafety, as severe side effects are rare [170, 171]. To date, two cases of thrombosis with thrombocytopenia syndrome (TTS) have been confirmed following Moderna's mRNA vaccination [171]. Other rare reported side effects after mRNA COVID-19 vaccination are myocarditis and pericarditis. These conditions, however, have been reported as rare events, appearing in $0.1 \%$ of vaccinated individuals [172]. As of October 27, 2021, 1,784 reports of myocarditis or pericarditis have been confirmed [171, 173]; further studies are necessary to evaluate whether there is a relationship between these rare adverse events and COVID-19 mRNA vaccination [174]. An additional concern during vaccine administration is the antibody-dependent enhancement (ADE) effect, which has been previously documented for some viral respiratory infections (e.g., syncytial and dengue virus) as it may decrease vaccine success and exacerbate disease [175]. Zhou et al. demonstrated that one group of RBD-specific antibodies found in one convalescent donor induced ADE of entry in Raji cells via an Fcy receptor-dependent mechanism [176]. Nevertheless, this study concluded that although the ADE effect for coronaviruses may be observed in vitro, a potential pathological relevance during SARS-CoV-2 infection seems unlikely [176].

\section{Conclusion}

SARS-CoV-2 represents a severe health risk to the world's population, and a rapid and multidisciplinary response has been necessary to overcome this pandemic. At the intersection of engineering and biology, medical nanotechnology, or nanomedicine, as it is more commonly referred to, has proven to be a versatile field that allows researchers to implement novel nanoscopic strategies against newevolving pathogens. Several biotechnology companies and academic institutions used nanotechnology for the successful design and development of mRNA vaccines against SARS-CoV-2. Based on these results, it is evident that the nanotechnology field has played a pivotal role to prevent further mortality, curtail the pandemic, and aid in the economic recovery of the world.

Acknowledgements The authors acknowledge the financial and scientific support of Brigham and Women's Hospital, Harvard Medical School and Massachusetts Institute of Technology. JVB is supported by NIH Grants R01DK072381, R37DK039773, and TR-002155. 
Funding Open access funding provided by Shanghai Jiao Tong University.

Open Access This article is licensed under a Creative Commons Attribution 4.0 International License, which permits use, sharing, adaptation, distribution and reproduction in any medium or format, as long as you give appropriate credit to the original author(s) and the source, provide a link to the Creative Commons licence, and indicate if changes were made. The images or other third party material in this article are included in the article's Creative Commons licence, unless indicated otherwise in a credit line to the material. If material is not included in the article's Creative Commons licence and your intended use is not permitted by statutory regulation or exceeds the permitted use, you will need to obtain permission directly from the copyright holder. To view a copy of this licence, visit http://creativecommons.org/licenses/by/4.0/.

\section{References}

1. J.K. Taubenberger, The origin and virulence of the 1918 "Spanish" influenza virus. Proc. Am. Philos. Soc. 150(1), 86-112 (2006)

2. E.C. Holmes, S.A. Goldstein, A.L. Rasmussen, D.L. Robertson, A. Crits-Christoph et al., The origins of SARSCoV-2: a critical review. Cell 184(19), 4848-4856 (2021). https://doi.org/10.1016/j.cell.2021.08.017

3. World Health Organization, Timeline of WHO's response to COVID-19. (WHO, 2020). Accessed 8 November 2021. https://www.who.int/news-room/detail/29-06-2020-covid timeline

4. World Health Organization, WHO coronavirus (COVID19) dashboard. (WHO, 2021). Accessed 8 November 2021. https://covid19.who.int/

5. J. Wolfram, M. Ferrari, Clinical cancer nanomedicine. Nano Today 25, 85-98 (2019). https://doi.org/10.1016/j. nantod.2019.02.005

6. D.M. Smith, J.K. Simon, J.R. Baker, Applications of nanotechnology for immunology. Nat. Rev. Immunol. 13(8), 592-605 (2013). https://doi.org/10.1038/nri3488

7. L.J. Cruz, P.J. Tacken, R. Fokkink, B. Joosten, M.C. Stuart et al., Targeted PLGA nano- but not microparticles specifically deliver antigen to human dendritic cells via DCSIGN in vitro. J. Control. Release 144(2), 118-126 (2010). https://doi.org/10.1016/j.jconrel.2010.02.013

8. A. Iwasaki, Antiviral immune responses in the genital tract: clues for vaccines. Nat. Rev. Immunol. 10(10), 699-711 (2010). https://doi.org/10.1038/nri2836

9. A.R. Fehr, S. Perlman, Coronaviruses: an overview of their replication and pathogenesis. Methods in Molecular Biology 1282, 1-23 (Humana Press, New York, 2015). https:// doi.org/10.1007/978-1-4939-2438-7_1

10. N. Wang, J. Shang, S. Jiang, L. Du, Subunit vaccines against emerging pathogenic human coronaviruses. Front.
Microbiol. 11, 298 (2020). https://doi.org/10.3389/fmicb. 2020.00298

11. K.G. Andersen, A. Rambaut, W.I. Lipkin, E.C. Holmes, R.F. Garry, The proximal origin of SARS-CoV-2. Nat. Med. 26(4), 450-452 (2020). https://doi.org/10.1038/ s41591-020-0820-9

12. L. Kuo, K.R. Hurst, P.S. Masters, Exceptional flexibility in the sequence requirements for coronavirus small envelope protein function. J. Virol. 81(5), 2249 (2007). https://doi.org/ 10.1128/JVI.01577-06

13. D. Schoeman, B.C. Fielding, Coronavirus envelope protein: current knowledge. Virol. J. 16, 69 (2019). https://doi.org/10. 1186/s12985-019-1182-0

14. M. Nishiga, D.W. Wang, Y. Han, D.B. Lewis, J.C. Wu, COVID-19 and cardiovascular disease: from basic mechanisms to clinical perspectives. Nat. Rev. Cardiol. 17(9), 543-558 (2020). https://doi.org/10.1038/s41569-020-0413-9

15. A. Gupta, M.V. Madhavan, K. Sehgal, N. Nair, S. Mahajan et al., Extrapulmonary manifestations of COVID-19. Nat. Med. 26(7), 1017-1032 (2020). https://doi.org/10.1038/ s41591-020-0968-3

16. M.Z. Tay, C.M. Poh, L. Rénia, P.A. MacAry, L.F.P. Ng, The trinity of COVID-19: immunity, inflammation and intervention. Nat. Rev. Immunol. 20(6), 363-374 (2020). https://doi. org/10.1038/s41577-020-0311-8

17. I. Hamming, W. Timens, M.L. Bulthuis, A.T. Lely, G. Navis et al., Tissue distribution of ACE2 protein, the functional receptor for SARS coronavirus, a first step in understanding SARS pathogenesis. J. Pathol. 203(2), 631-637 (2004). https://doi.org/10.1002/path.1570

18. H.P. Jia, D.C. Look, L. Shi, M. Hickey, L. Pewe et al., ACE2 receptor expression and severe acute respiratory syndrome coronavirus infection depend on differentiation of human airway epithelia. J. Virol. 79(23), 14614-14621 (2005). https:// doi.org/10.1128/JVI.79.23.14614-14621.2005

19. M. Hoffmann, H. Kleine-Weber, S. Schroeder, N. Kruger, T. Herrler et al., SARS-CoV-2 cell entry depends on ACE2 and TMPRSS 2 and is blocked by a clinically proven protease inhibitor. Cell 181(2), 271-280 (2020). https://doi.org/ 10.1016/j.cell.2020.02.052

20. R.J. Mason, Pathogenesis of COVID-19 from a cell biology perspective. Eur. Respir. J. 55(4), 2000607 (2020). https:// doi.org/10.1183/13993003.00607-2020

21. A. Heurich, H. Hofmann-Winkler, S. Gierer, T. Liepold, O. Jahn et al., TMPRSS2 and ADAM17 cleave ACE2 differentially and only proteolysis by TMPRSS2 augments entry driven by the severe acute respiratory syndrome coronavirus spike protein. J. Virol. 88(2), 1293-1307 (2014). https://doi. org/10.1128/JVI.02202-13

22. R. Zang, M.F.G. Castro, B.T. McCune, Q. Zeng, P.W. Rothlauf et al., TMPRSS2 and TMPRSS4 promote SARS-CoV-2 infection of human small intestinal enterocytes. Sci. Immunol. 5(47), abc3582 (2020). https://doi.org/10.1126/sciim munol.abc3582 
23. Z.Y. Yang, Y. Huang, L. Ganesh, K. Leung, W.P. Kong et al., pH-dependent entry of severe acute respiratory syndrome coronavirus is mediated by the spike glycoprotein and enhanced by dendritic cell transfer through DC-SIGN. J. Virol. 78(11), 5642-5650 (2004). https://doi.org/10.1128/ JVI.78.11.5642-5650.2004

24. D.A. Groneberg, R. Hilgenfeld, P. Zabel, Molecular mechanisms of severe acute respiratory syndrome (SARS). Respir. Res. 6, 8 (2005). https://doi.org/10.1186/1465-9921-6-8

25. H.A. Rothan, S.N. Byrareddy, The epidemiology and pathogenesis of coronavirus disease (COVID-19) outbreak. J. Autoimmun. 109, 102433 (2020). https://doi.org/10.1016/j. jaut.2020.102433

26. W.T. Harvey, A.M. Carabelli, B. Jackson, R.K. Gupta, E.C. Thomson et al., SARS-CoV-2 variants, spike mutations and immune escape. Nat. Rev. Microbiol. 19(7), 409-424 (2021). https://doi.org/10.1038/s41579-021-00573-0

27. A.J. Greaney, A.N. Loes, K.H.D. Crawford, T.N. Starr, K.D. Malone et al., Comprehensive mapping of mutations in the SARS-CoV-2 receptor-binding domain that affect recognition by polyclonal human plasma antibodies. Cell Host Microbe. 29(3), 463-476 (2021). https://doi.org/10.1016/j.chom.2021. 02.003

28. E.C. Sabino, L.F. Buss, M.P.S. Carvalho, C.A. Prete, M.A.E. Crispim et al., Resurgence of COVID-19 in Manaus, Brazil, despite high seroprevalence. Lancet 397(10273), 452-455 (2021). https://doi.org/10.1016/S0140-6736(21)00183-5

29. H. Tegally, E. Wilkinson, M. Giovanetti, A. Iranzadeh, V. Fonseca et al., Emergence and rapid spread of a new severe acute respiratory syndrome-related coronavirus 2 (SARS$\mathrm{CoV}-2)$ lineage with multiple spike mutations in South Africa. medRxiv, (2020). https://doi.org/10.1101/2020.12. 21.20248640

30. E. Volz, S. Mishra, M. Chand, J.C. Barrett, R. Johnson et al., Transmission of SARS-CoV-2 lineage B.1.1.7 in England: insights from linking epidemiological and genetic data. medRxiv, (2021). https://doi.org/10.1101/2020.12.30.20249 034

31. P. Wang, M.S. Nair, L. Liu, S. Iketani, Y. Luo et al., Antibody resistance of SARS-CoV-2 variants B1.351 and B.1.1.7. Nature 593(7857), 130-135 (2021). https://doi.org/10.1038/ s41586-021-03398-2

32. D. Zhou, W. Dejnirattisai, P. Supasa, C. Liu, A.J. Mentzer et al., Evidence of escape of SARS-CoV-2 variant B.1.351 from natural and vaccine-induced sera. Cell 184(9), 23482361 (2021). https://doi.org/10.1016/j.cell.2021.02.037

33. Centers for Disease Control and Prevention, Interim clinical guidance for management of patients with confirmed coronavirus disease (COVID-19). (CDC, 2020). https://www.cdc. gov/coronavirus/2019-ncov/hcp/clinical-guidance-manag ement-patients.html

34. S. Zaim, J.H. Chong, V. Sankaranarayanan, A. Harky, COVID-19 and multiorgan response. Curr. Probl. Cardiol. 45(8), 100618 (2020). https://doi.org/10.1016/j.cpcardiol. 2020.100618
35. Mayo Clinic, Coronavirus disease 2019 (COVID-19). (Mayo Clinic, 2020). https://www.mayoclinic.org/diseases-condi tions/coronavirus/symptoms-causes/syc-20479963

36. M.D. Bhavsar, M.M. Amiji, Polymeric nano- and microparticle technologies for oral gene delivery. Expert Opin. Drug Deliv. 4(3), 197-213 (2007). https://doi.org/10.1517/17425 247.4.3.197

37. K.E. Bissati, Y. Zhou, S.M. Paulillo, S.K. Raman, C.P. Karch et al., Protein nanovaccine confers robust immunity against Toxoplasma. npj Vaccines 2, 24 (2017). https://doi.org/10. 1038/s41541-017-0024-6

38. M. Amidi, S.G. Romeijn, J.C. Verhoef, H.E. Junginger, L. Bungener et al., N-trimethyl chitosan (TMC) nanoparticles loaded with influenza subunit antigen for intranasal vaccination: biological properties and immunogenicity in a mouse model. Vaccine 25(1), 144-153 (2007). https://doi.org/10. 1016/j.vaccine.2006.06.086

39. Y. Guo, D. Wang, Q. Song, T. Wu, X. Zhuang et al., Erythrocyte membrane-enveloped polymeric nanoparticles as nanovaccine for induction of antitumor immunity against melanoma. ACS Nano 9(7), 6918-6933 (2015). https://doi. org/10.1021/acsnano.5b01042

40. S. Jong, G. Chikh, L. Sekirov, S. Raney, S. Semple et al., Encapsulation in liposomal nanoparticles enhances the immunostimulatory, adjuvant and anti-tumor activity of subcutaneously administered CpG ODN. Cancer Immunol. Immunother. 56(8), 1251-1264 (2007). https://doi.org/10. 1007/s00262-006-0276-x

41. E. Farris, D.M. Brown, A.E. Ramer-Tait, A.K. Pannier, Micro- and nanoparticulates for DNA vaccine delivery. Exp. Biol. Med. 241(9), 919-929 (2016). https://doi.org/10.1177/ 1535370216643771

42. D. Chenthamara, S. Subramaniam, S.G. Ramakrishnan, S. Krishnaswamy, M.M. Essa et al., Therapeutic efficacy of nanoparticles and routes of administration. Biomater. Res. 23, 20 (2019). https://doi.org/10.1186/s40824-019-0166-X

43. J. Lu, G. Lu, S. Tan, J. Xia, H. Xiong et al., A COVID-19 mRNA vaccine encoding SARS-CoV-2 virus-like particles induces a strong antiviral-like immune response in mice. Cell Res. 30(10), 936-939 (2020). https://doi.org/10.1038/ s41422-020-00392-7

44. A.C. Anselmo, S. Mitragotri, Nanoparticles in the clinic: an update. Bioeng. Transl. Med. 4(3), e10143 (2019). https:// doi.org/10.1002/btm2.10143

45. L. Sercombe, T. Veerati, F. Moheimani, S.Y. Wu, A.K. Sood et al., Advances and challenges of liposome assisted drug delivery. Front. Pharmacol. 6, 286 (2015). https://doi.org/10. 3389/fphar.2015.00286

46. R. Tenchov, R. Bird, A.E. Curtze, Q. Zhou, Lipid nanoparticles-from liposomes to mRNA vaccine selivery, a landscape of research diversity and advancement. ACS Nano (2021). https://doi.org/10.1021/acsnano.1c04996

47. R. Tenchov, R. Bird, A.E. Curtze, Q. Zhou, Lipid nanoparticles-from liposomes to mRNA vaccine delivery, a landscape 
of research diversity and advancement. ACS Nano (2021). https://doi.org/10.1021/acsnano.1c04996

48. C. Rinoldi, S.S. Zargarian, P. Nakielski, X. Li, A. Liguori et al., Nanotechnology-assisted RNA delivery: from nucleic acid therapeutics to COVID-19 vaccines. Small Methods 5(9), 2100402 (2021). https://doi.org/10.1002/smtd.20210 0402

49. Editorial, Let's talk about lipid nanoparticles. Nat. Rev. Mater. 6(2), 99 (2021). https://doi.org/10.1038/s41578-021-00281-4

50. O.S. Fenton, K.N. Olafson, P.S. Pillai, M.J. Mitchell, R. Langer, Advances in biomaterials for drug delivery. Adv. Mater. 30(29), 1705328 (2018). https://doi.org/10.1002/ adma.201705328

51. X. Cheng, R.J. Lee, The role of helper lipids in lipid nanoparticles (LNPs) designed for oligonucleotide delivery. Adv. Drug Deliv. Rev. 99, 129-137 (2016). https://doi.org/10. 1016/j.addr.2016.01.022

52. S.M. Moghimi, Allergic reactions and anaphylaxis to LNPbased COVID-19 vaccines. Mol. Ther. 29(3), 898-900 (2021). https://doi.org/10.1016/j.ymthe.2021.01.030

53. L.P. Mendes, J. Pan, V.P. Torchilin, Dendrimers as nanocarriers for nucleic acid and drug delivery in cancer therapy. Molecules 22(9), 1401 (2017). https://doi.org/10.3390/molec ules22091401

54. M.J. Mitchell, M.M. Billingsley, R.M. Haley, M.E. Wechsler, N.A. Peppas et al., Engineering precision nanoparticles for drug delivery. Nat. Rev. Drug Discov. 20(2), 101-124 (2021). https://doi.org/10.1038/s41573-020-0090-8

55. F. Alexis, E. Pridgen, L.K. Molnar, O.C. Farokhzad, Factors affecting the clearance and biodistribution of polymeric nanoparticles. Mol. Pharm. 5(4), 505-515 (2008). https://doi. org/10.1021/mp800051m

56. J.K. Patra, G. Das, L.F. Fraceto, E.V.R. Campos, M.P. Rodriguez-Torres et al., Nano based drug delivery systems: recent developments and future prospects. J. Nanobiotechnology. 16(1), 71 (2018). https://doi.org/10.1186/s12951-018-0392-8

57. A.M. Jhaveri, V.P. Torchilin, Multifunctional polymeric micelles for delivery of drugs and siRNA. Front. Pharmacol. 5, 77 (2014). https://doi.org/10.3389/fphar.2014.00077

58. E. Rideau, R. Dimova, P. Schwille, F.R. Wurm, K. Landfester, Liposomes and polymersomes: a comparative review towards cell mimicking. Chem. Soc. Rev. 47(23), 8572-8610 (2018). https://doi.org/10.1039/c8cs00162f

59. Z. Mhlwatika, B.A. Aderibigbe, Application of dendrimers for the treatment of infectious diseases. Molecules 23(9), 2205 (2018). https://doi.org/10.3390/molecules23092205

60. I. Tariq, M.Y. Ali, M.F. Sohail, M.U. Amin, S. Ali et al., Lipodendriplexes mediated enhanced gene delivery: a cellular to pre-clinical investigation. Sci. Rep. 10(1), 21446 (2020). https://doi.org/10.1038/s41598-020-78123-6

61. J. Chen, A. Ellert-Miklaszewska, S. Garofalo, A.K. Dey, J. Tang et al., Synthesis and use of an amphiphilic dendrimer for siRNA delivery into primary immune cells. Nat. Protoc. 16(1), 327-351 (2021). https://doi.org/10.1038/ s41596-020-00418-9
62. S. Ahn, I.H. Lee, S. Kang, D. Kim, M. Choi et al., Gold nanoparticles displaying tumor-associated self-antigens as a potential vaccine for cancer immunotherapy. Adv. Healthc. Mater. 3(8), 1194-1199 (2014). https://doi.org/10.1002/ adhm.201300597

63. R. Gottardi, B. Douradinha, Carbon nanotubes as a novel tool for vaccination against infectious diseases and cancer. J. Nanobiotechn. 11, 30 (2013). https://doi.org/10.1186/ 1477-3155-11-30

64. K.L. Hess, I.L. Medintz, C.M. Jewell, Designing inorganic nanomaterials for vaccines and immunotherapies. Nano Today 27, 73-98 (2019). https://doi.org/10.1016/j.nantod. 2019.04.005

65. A.K. Pearce, T.R. Wilks, M.C. Arno, R.K. O'Reilly, Synthesis and applications of anisotropic nanoparticles with precisely defined dimensions. Nat. Rev. Chem. 5(1), 21-45 (2021). https://doi.org/10.1038/s41570-020-00232-7

66. A.M. Wagner, J.M. Knipe, G. Orive, N.A. Peppas, Quantum dots in biomedical applications. Acta Biomater. 94, 44-63 (2019). https://doi.org/10.1016/j.actbio.2019.05.022

67. R. Kumar, P.C. Ray, D. Datta, G.P. Bansal, E. Angov et al., Nanovaccines for malaria using Plasmodium falciparum antigen Pfs25 attached gold nanoparticles. Vaccine 33(39), 5064-5071 (2015). https://doi.org/10.1016/j.vaccine.2015. 08.025

68. D. Pissuwan, T. Niidome, M.B. Cortie, The forthcoming applications of gold nanoparticles in drug and gene delivery systems. J. Control. Release 149(1), 65-71 (2011). https://doi.org/10.1016/j.jconrel.2009.12.006

69. D. Bobo, K.J. Robinson, J. Islam, K.J. Thurecht, S.R. Corrie, Nanoparticle-based medicines: a review of FDAapproved materials and clinical trials to date. Pharm. Res. 33(10), 2373-2387 (2016). https://doi.org/10.1007/ s11095-016-1958-5

70. F. Yu, J. Wang, J. Dou, H. Yang, X. He et al., Nanoparticlebased adjuvant for enhanced protective efficacy of DNA vaccine Ag85A-ESAT-6-IL-21 against Mycobacterium tuberculosis infection. Nanomed. Nanotechnol. Biol. Med. 8(8), 1337-1344 (2012). https://doi.org/10.1016/j.nano. 2012.02.015

71. K.J. McHugh, L. Jing, S.Y. Severt, M. Cruz, M. Sarmadi et al., Biocompatible near-infrared quantum dots delivered to the skin by microneedle patches record vaccination. Sci. Transl. Med. 11(523), aay7162 (2019). https://doi.org/10. 1126/scitranslmed.aay7162

72. E.M. Plummer, M. Manchester, Viral nanoparticles and virus-like particles: platforms for contemporary vaccine design. Wiley Interdiscip. Rev. Nanomed. Nanobiotechnol. 3(2), 174-196 (2011). https://doi.org/10.1002/wnan.119

73. S. Chattopadhyay, J.Y. Chen, H.W. Chen, C.M.J. Hu, Nanoparticle vaccines adopting virus-like features for enhanced immune potentiation. Nanotheranostics 1(3), 244-260 (2017). https://doi.org/10.7150/ntno.19796 
74. M. Perotti, L. Perez, Virus-like particles and nanoparticles for vaccine development against HCMV. Viruses 12(1), 35 (2019). https://doi.org/10.3390/v12010035

75. J. Yang, X. Zhang, C. Liu, Z. Wang, L. Deng et al., Biologically modified nanoparticles as theranostic bionanomaterials. Prog. Mater. Sci. 118, 100768 (2021). https://doi.org/ 10.1016/j.pmatsci.2020.100768

76. M.D. Shin, S. Shukla, Y.H. Chung, V. Beiss, S.K. Chan et al., COVID-19 vaccine development and a potential nanomaterial path forward. Nat. Nanotechnol. 15(8), 646655 (2020). https://doi.org/10.1038/s41565-020-0737-y

77. L. Xu, Y. Liu, Z. Chen, W. Li, Y. Liu et al., Morphologically virus-like fullerenol nanoparticles act as the dual-functional nanoadjuvant for HIV-1 vaccine. Adv. Mater. 25(41), 59285936 (2013). https://doi.org/10.1002/adma.201300583

78. R. Ribeiro-Viana, M. Sánchez-Navarro, J. Luczkowiak, J.R. Koeppe, R. Delgado et al., Virus-like glycodendrinanoparticles displaying quasi-equivalent nested polyvalency upon glycoprotein platforms potently block viral infection. Nat. Commun. 3(1), 1303 (2012). https://doi.org/10.1038/ncomm s2302

79. W. Wang, X. Zhou, Y. Bian, S. Wang, Q. Chai et al., Dualtargeting nanoparticle vaccine elicits a therapeutic antibody response against chronic hepatitis B. Nat. Nanotechnol. 15(5), 406-416 (2020). https://doi.org/10.1038/s41565-020-0648-y

80. E.A. Evtushenko, E.M. Ryabchevskaya, N.A. Nikitin, J.G. Atabekov, O.V. Karpova, Plant virus particles with various shapes as potential adjuvants. Sci. Rep. 10(1), 10365 (2020). https://doi.org/10.1038/s41598-020-67023-4

81. M.O. Mohsen, I. Balke, S. Zinkhan, V. Zeltina, X. Liu et al., A scalable and highly immunogenic virus-like particle-based vaccine against SARS-CoV-2. Allergy (2021). https://doi.org/ 10.1111/all.15080

82. A. Biddlecome, H.H. Habte, K.M. McGrath, S. Sambanthamoorthy, M. Wurm et al., Delivery of self-amplifying RNA vaccines in in vitro reconstituted virus-like particles. PLoS ONE 14(6), e0215031 (2019). https://doi.org/10.1371/journ al.pone.0215031

83. C. Qian, X. Liu, Q. Xu, Z. Wang, J. Chen et al., Recent progress on the versatility of virus-like particles. Vaccines $\mathbf{8}(1)$, 139 (2020). https://doi.org/10.3390/vaccines8010139

84. H. Garg, T. Mehmetoglu-Gurbuz, A. Joshi, Virus like particles (VLP) as multivalent vaccine candidate against chikungunya, Japanese encephalitis, yellow fever and Zika virus. Sci. Rep. 10(1), 4017 (2020). https://doi.org/10.1038/ s41598-020-61103-1

85. C.N. Fries, E.J. Curvino, J.L. Chen, S.R. Permar, G.G. Fouda et al., Advances in nanomaterial vaccine strategies to address infectious diseases impacting global health. Nat. Nanotechnol. 16(4), 1-14 (2021). https://doi.org/10.1038/ s41565-020-0739-9

86. P. Krause, T.R. Fleming, I. Longini, A.M. Henao-Restrepo, R. Peto et al., COVID-19 vaccine trials should seek worthwhile efficacy. Lancet 396(10253), 741-743 (2020). https://doi.org/ $10.1016 / \mathrm{S} 0140-6736(20) 31821-3$
87. World Health Organization, Draft landscape and tracker of COVID-19 candidate vaccines. (WHO, 2021). https://www. who.int/publications/m/item/draft-landscape-of-covid-19candidate-vaccines

88. S. Han, Clinical vaccine development. Clin. Exp. Vaccine Res. 4(1), 46-53 (2015). https://doi.org/10.7774/cevr.2015.4. 1.46

89. U.S. Food and Drug Administration, Vaccine product approval process. (Silver Spring: U.S. Food and Drug Administration, 2014). https://www.fda.gov/vaccinesblood-biologics/development-approval-process-cber/vacci ne-product-approval-process

90. K. Singh, S. Mehta, The clinical development process for a novel preventive vaccine: an overview. J. Postgrad. Med. 62(1), 4-11 (2016). https://doi.org/10.4103/0022-3859. 173187

91. World Health Organization, Guidelines on clinical evaluation of vaccines: regulatory expectations. (WHO, 2020). https://www.who.int/publications/m/item/ WHO-TRS-1004-web-annex-9

92. Centers for Disease Control and Prevention, Vaccine testing and the approval process. (National Center for Immunization and Respiratory Diseases (NCIRD), 2014). https:// www.cdc.gov/vaccines/basics/test-approve.html

93. C.H. Wong, K.W. Siah, A.W. Lo, Estimation of clinical trial success rates and related parameters. Biostatistics 20(2), 273-286 (2019). https://doi.org/10.1093/biostatist ics/kxx069

94. Centers for Disease Control and Prevention, Epidemiology and prevention of vaccine-preventable diseases: mumps. (CDC, 2019). https://www.cdc.gov/vaccines/pubs/pinkb ook/mumps.html

95. R. Khamsi, If a coronavirus vaccine arrives, can the world make enough? Nature 580(7805), 578-580 (2020). https:// doi.org/10.1038/d41586-020-01063-8

96. Moderna, Moderna receives FDA fast track designation for mRNA vaccine (mRNA-1273) against novel coronavirus. (Moderna, 2020). https://investors.modernatx.com/ news-releases/news-release-details/moderna-receives-fdafast-track-designation-mrna-vaccine-mrna\#: :text $=\% 2 \mathrm{D} \%$ 2D(BUSINESS\%20WIRE)\%2D\%2DMay,FDA) \%20has\% 20granted $\% 20$ Fast $\% 20$ Track

97. Pfizer, Pfizer and BioNTech granted FDA fast track designation for two investigational mRNA-based vaccine candidates against SARS-CoV-2. (Pfizer, 2020). https://www. pfizer.com/news/press-release/press-release-detail/pfizerand-biontech-granted-fda-fast-track-designation-two

98. G. Forni, A. Mantovani, G. Forni, A. Mantovani, L. Moretta et al., COVID-19 vaccines: where we stand and challenges ahead. Cell Death Differ. 28(2), 626-639 (2021). https:// doi.org/10.1038/s41418-020-00720-9

99. N. Thiel, C. Selwyn, G. Murphy, S. Simpson, A.C. Chakrabarti, Recommendations for acceleration of vaccine development and emergency use filings for COVID19 leveraging lessons from the novel oral polio vaccine. 
npj Vaccines 6(1), 63 (2021). https://doi.org/10.1038/ s41541-021-00325-4

100. A. Bolhassani, S.R. Yazdi, DNA immunization as an efficient strategy for vaccination. Avicenna J. Med. Biotechnol. 1(2), 71-88 (2009)

101. N. Pardi, M.J. Hogan, F.W. Porter, D. Weissman, mRNA vaccines: a new era in vaccinology. Nat. Rev. Drug Discov. 17(4), 261-279 (2018). https://doi.org/10.1038/nrd.2017.243

102. C. Zhang, G. Maruggi, H. Shan, J. Li, Advances in mRNA vaccines for infectious diseases. Front. Immunol. 10, 594 (2019). https://doi.org/10.3389/fimmu.2019.00594

103. N.P. Restifo, H. Ying, L. Hwang, W.W. Leitner, The promise of nucleic acid vaccines. Gene Ther. 7(2), 89-92 (2000). https://doi.org/10.1038/sj.gt.3301117

104. K. Zhao, G. Rong, Y. Hao, L. Yu, H. Kang et al., IgA response and protection following nasal vaccination of chickens with Newcastle disease virus DNA vaccine nanoencapsulated with $\mathrm{Ag} @ \mathrm{SiO}_{2}$ hollow nanoparticles. Sci. Rep. 6(1), 25720 (2016). https://doi.org/10.1038/srep25720

105. S. Boyoglu, K. Vig, S. Pillai, V. Rangari, V.A. Dennis et al., Enhanced delivery and expression of a nanoencapsulated DNA vaccine vector for respiratory syncytial virus. Nanomed. Nanotechnol. Biol. Med. 5(4), 463-472 (2009). https://doi.org/10.1016/j.nano.2009.02.004

106. D.S. Watson, A.N. Endsley, L. Huang, Design considerations for liposomal vaccines: influence of formulation parameters on antibody and cell-mediated immune responses to liposome associated antigens. Vaccine 30(13), 2256-2272 (2012). https://doi.org/10.1016/j.vaccine.2012.01.070

107. K. Hadinoto, A. Sundaresan, W.S. Cheow, Lipid-polymer hybrid nanoparticles as a new generation therapeutic delivery platform: a review. Eur. J. Pharm. Biopharm. 85(3), 427-443 (2013). https://doi.org/10.1016/j.ejpb.2013.07.002

108. N. Armbruster, E. Jasny, B. Petsch, Advances in RNA vaccines for preventive indications: a case study of a vaccine against rabies. Vaccines 7(4), 132 (2019). https://doi.org/10. 3390/vaccines7040132

109. H.H. Gustafson, D. Holt-Casper, D.W. Grainger, H. Ghandehari, Nanoparticle uptake: the phagocyte problem. Nano Today 10(4), 487-510 (2015). https://doi.org/10.1016/j.nantod.2015.06.006

110. S. Rauch, E. Jasny, K.E. Schmidt, B. Petsch, New vaccine technologies to combat outbreak situations. Front. Immunol. 9, 1963 (2018). https://doi.org/10.3389/fimmu.2018.01963

111. I. Yanagihara, Y. Kaneda, K. Inui, S. Okada, Liposome-mediated gene transfer. Molecular and Cell Biology of Human Gene Therapeutics, 64-82 (Springer, Dordrecht, 1995). https://doi.org/10.1007/978-94-011-0547-7_4

112. D.W. Pack, A.S. Hoffman, S. Pun, P.S. Stayton, Design and development of polymers for gene delivery. Nat. Rev. Drug Discov. 4(7), 581-593 (2005). https://doi.org/10.1038/nrd17 75

113. A. Wadhwa, A. Aljabbari, A. Lokras, C. Foged, A. Thakur, Opportunities and challenges in the delivery of mRNA-based vaccines. Pharmaceutics 12(2), 102 (2020). https://doi.org/ 10.3390/pharmaceutics 12020102

114. W.B. Liechty, N.A. Peppas, Expert opinion: responsive polymer nanoparticles in cancer therapy. Eur. J. Pharm. Biopharm. 80(2), 241-246 (2012). https://doi.org/10.1016/j.ejpb. 2011.08.004

115. L. Versteeg, M.M. Almutairi, P.J. Hotez, J. Pollet, Enlisting the mRNA vaccine platform to combat parasitic infections. Vaccines 7(4), 122 (2019). https://doi.org/10.3390/vacci nes7040122

116. D. Hobernik, M. Bros, DNA vaccines-how far from clinical use? Int. J. Mol. Sci. 19(11), 3605 (2018). https://doi.org/10. 3390/ijms19113605

117. G. Dauphin, S. Zientara, West Nile virus: recent trends in diagnosis and vaccine development. Vaccine 25(30), 55635576 (2007). https://doi.org/10.1016/j.vaccine.2006.12.005

118. M.A. Kutzler, D.B. Weiner, DNA vaccines: ready for prime time? Nat. Rev. Genet. 9(10), 776-788 (2008). https://doi. org/10.1038/nrg2432

119. L.M. Kranz, M. Diken, H. Haas, S. Kreiter, C. Loquai et al., Systemic RNA delivery to dendritic cells exploits antiviral defence for cancer immunotherapy. Nature 534(7607), 396-401 (2016). https://doi.org/10.1038/nature 18300

120. K. Bahl, J.J. Senn, O. Yuzhakov, A. Bulychev, L.A. Brito et al., Preclinical and clinical demonstration of immunogenicity by mRNA vaccines against $\mathrm{H} 10 \mathrm{~N} 8$ and H7N9 influenza viruses. Mol. Ther. 25(6), 1316-1327 (2017). https://doi.org/10.1016/j.ymthe.2017.03.035

121. J.M. Richner, S. Himansu, K.A. Dowd, S.L. Butler, V. Salazar et al., Modified mRNA vaccines protect against Zika virus infection. Cell 168(6), 1114-1125 (2017). https://doi. org/10.1016/j.cell.2017.02.017

122. J.A. Wolff, R.W. Malone, P. Williams, W. Chong, G. Acsadi et al., Direct gene transfer into mouse muscle in vivo. Science 247(4949), 1465-1468 (1990). https://doi.org/10. $1126 /$ science. 1690918

123. C. Iavarone, D.T. O’Hagan, D. Yu, N.F. Delahaye, J.B. Ulmer, Mechanism of action of mRNA-based vaccines. Expert Rev. Vaccines 16(9), 871-881 (2017). https://doi. org/10.1080/14760584.2017.1355245

124. Pfizer, COVID-19 R\&D presentation. (Pfizer, 2020). Accessed 8 November 2021. https://s21.q4cdn.com/31767 8438/files/doc_presentations/2020/09/Covid-19-Programs_ FINAL.pdf

125. U.S. National Library of Medicine, Study to describe the safety, tolerability, immunogenicity, and potential efficacy of RNA vaccine candidates against COVID-19 in healthy adults. (NIH, 2020). Accessed 8 November 2021. https:// clinicaltrials.gov/ct2/show/NCT04368728

126. J. Hodgson, The pandemic pipeline. Nat. Biotechnol. 38(5), 523-532 (2020). https://doi.org/10.1038/ d41587-020-00005-z

127. A.B. Vogel, I. Kanevsky, Y. Che, K.A. Swanson, A. Muik et al., BNT162b vaccines protect rhesus macaques from 
SARS-CoV-2. Nature 592(7853), 283-289 (2021). https:// doi.org/10.1038/s41586-021-03275-y

128. NIH. A Trial Investigating the Safety and Effects of Four BNT162 Vaccines Against COVID-2019 in Healthy and Immunocompromised Adults, (2020).

129. M.J. Mulligan, K.E. Lyke, N. Kitchin, J. Absalon, A. Gurtman et al., Phase I/II study of COVID-19 RNA vaccine BNT162b1 in adults. Nature 586(7830), 589-593 (2020). https://doi.org/10.1038/s41586-020-2639-4

130. S. Güthe, L. Kapinos, A. Möglich, S. Meier, S. Grzesiek et al., Very fast folding and association of a trimerization domain from bacteriophage T4 fibritin. J. Mol. Biol. 337(4), 905-915 (2004). https://doi.org/10.1016/j.jmb.2004.02.020

131. U. Sahin, A. Muik, E. Derhovanessian, I. Vogler, L.M. Kranz et al., Concurrent human antibody and Th1 type T-cell responses elicited by a COVID-19 RNA vaccine. medRxiv (2020). https://doi.org/10.1101/2020.07.17.20140 533

132. Pfizer, Pfizer and BioNTech choose lead mRNA vaccine candidate against COVID-19 and commence pivotal Phase 2/3 global study. (Pfizer, 2020). Accessed 8 November 2021. https://www.pfizer.com/news/press-release/pressrelease-detail/pfizer-and-biontech-choose-lead-mrna-vacci ne-candidate- 0

133. F.P. Polack, S.J. Thomas, N. Kitchin, J. Absalon, A. Gurtman et al., Safety and efficacy of the BNT162b2 mRNA covid-19 vaccine. N. Engl. J. Med. 383(27), 2603-2615 (2020). https://doi.org/10.1056/NEJMoa2034577

134. L.J. Abu-Raddad, H. Chemaitelly, A.A. Butt, Effectiveness of the BNT162b2 Covid-19 vaccine against the B.1.1.7 and B.1.351 variants. N. Engl. J. Med. 385(2), 187-189 (2021). https://doi.org/10.1056/NEJMc2104974

135. Z. Wang, F. Schmidt, Y. Weisblum, F. Muecksch, C.O. Barnes et al., mRNA vaccine-elicited antibodies to SARSCoV-2 and circulating variants. Nature 592(7855), 616-622 (2021). https://doi.org/10.1038/s41586-021-03324-6

136. K.S. Corbett, D.K. Edwards, S.R. Leist, O.M. Abiona, S. Boyoglu-Barnum et al., SARS-CoV-2 mRNA vaccine design enabled by prototype pathogen preparedness. Nature 586(7830), 567-571 (2020). https://doi.org/10.1038/s41586-020-2622-0

137. V.A. Fulginiti, J.J. Eller, A.W. Downie, C.H. Kempe, Altered reactivity to measles virus: atypical measles in children previously immunized with inactivated measles virus vaccines. JAMA 202(12), 1075-1080 (1967). https://doi.org/10.1001/ jama.1967.03130250057008

138. H.W. Kim, J.G. Canchola, C.D. Brandt, G. Pyles, R.M. Chanock et al., Respiratory syncytial virus disease in infants despite prior administration of antigenic inactivated vaccine. Am. J. Epidemiol. 89(4), 422-434 (1969). https://doi.org/10. 1093/oxfordjournals.aje.a120955

139. K.S. Corbett, B. Flynn, K.E. Foulds, J.R. Francica, S. Boyoglu-Barnum et al., Evaluation of the mRNA-1273 vaccine against SARS-CoV-2 in nonhuman primates. N. Engl. J. Med. 383(16), 1544-1555 (2020). https://doi.org/10.1056/NEJMo a2024671
140. National Institute of Allergy and Infectious Diseases. Safety and Immunogenicity Study of 2019-nCoV Vaccine (mRNA1273) for Prophylaxis of SARS-CoV-2 Infection (COVID19), U.S. National Library of Medicine, (2020).

141. Moderna, Moderna announces positive interim phase 1 data for its mRNA vaccine (mRNA-1273) against novel coronavirus. (Moderna, 2020). Accessed 8 November 2021. https:// investors.modernatx.com/news-releases/news-release-details/ moderna-announces-positive-interim-phase-1-data-its-mrnavaccine/

142. L.A. Jackson, E.J. Anderson, N.G. Rouphael, P.C. Roberts, M. Makhene et al., An mRNA vaccine against SARSCoV-2 - preliminary report. N. Engl. J. Med. 383(20), 1920-1931 (2020). https://doi.org/10.1056/NEJMoa2022 483

143. U.S. National Library of Medicine, Dose-confirmation study to evaluate the safety, reactogenicity, and immunogenicity of mRNA-1273 COVID-19 vaccine in adults aged 18 years and older. (2020). Accessed 8 November 2021. https://clinicaltrials.gov/ct2/show/NCT04405076

144. L. Chu, R. McPhee, W. Huang, H. Bennett, R. Pajon et al., A preliminary report of a randomized controlled phase 2 trial of the safety and immunogenicity of mRNA-1273 SARS-CoV-2 vaccine. Vaccine 39(20), 2791-2799 (2021). https://doi.org/10.1016/j.vaccine.2021.02.007

145. E.J. Anderson, N.G. Rouphael, A.T. Widge, L.A. Jackson, P.C. Roberts et al., Safety and immunogenicity of SARSCoV-2 mRNA-1273 vaccine in older adults. N. Engl. J. Med. 383(25), 2427-2438 (2020). https://doi.org/10.1056/ NEJMoa2028436

146. L.R. Baden, H.M.E. Sahly, B. Essink, K. Kotloff, S. Frey et al., Efficacy and safety of the mRNA-1273 SARS-CoV-2 vaccine. N. Engl. J. Med. 384(5), 403-416 (2021). https:// doi.org/10.1056/NEJMoa2035389

147. Moderna, Moderna announces positive initial booster data against SARS-CoV-2 variants of concern. (Moderna, 2021). Accessed 8 November 2021. https://investors.modernatx. com/news-releases/news-release-details/moderna-annou nces-positive-initial-booster-data-against-sars-cov/

148. X. Hou, T. Zaks, R. Langer, Y. Dong, Lipid nanoparticles for mRNA delivery. Nat. Rev. Mater. (2021). https://doi. org/10.1038/s41578-021-00358-0

149. E. Blanco, H. Shen, M. Ferrari, Principles of nanoparticle design for overcoming biological barriers to drug delivery. Nat. Biotechnol. 33(9), 941-951 (2015). https://doi.org/10. 1038/nbt.3330

150. Z.I. Rajput, S.H. Hu, C.W. Xiao, A.G. Arijo, Adjuvant effects of saponins on animal immune responses. J. Zhejiang Univ. Sci. B 8(3), 153-161 (2007). https://doi.org/10. 1631/jzus.2007.B0153

151. B. Petsch, M. Schnee, A.B. Vogel, E. Lange, B. Hoffmann et al., Protective efficacy of in vitro synthesized, specific mRNA vaccines against influenza A virus infection. Nat. Biotechnol. 30(12), 1210-1216 (2012). https://doi.org/10. 1038/nbt.2436 
152. N.C. Kyriakidis, A. López-Cortés, E.V. González, A.B. Grimaldos, E.O. Prado, SARS-CoV-2 vaccines strategies: a comprehensive review of phase 3 candidates. npj Vaccines 6(1), 28 (2021). https://doi.org/10.1038/s41541-021-00292-w

153. R.T. Shroff, P. Chalasani, R. Wei, D. Pennington, G. Quirk et al., Immune responses to two and three doses of the BNT162b2 mRNA vaccine in adults with solid tumors. Nat. Med. (2021). https://doi.org/10.1038/s41591-021-01542-z

154. U.S. Food and Drug Administration, FDA Authorizes PfizerBioNTech COVID-19 vaccine for emergency use in children 5 through 11 years of age. (FDA, 2021). Accessed 8 November 2021. https://www.fda.gov/news-events/press-annou ncements/fda-authorizes-pfizer-biontech-covid-19-vaccineemergency-use-children-5-through-11-years-age\#: :text= Press\%20Announcements-,FDA\%20Authorizes\%20Pfizer\% 2DBioNTech\%20COVID\%2D19\%20Vaccine\%20for\%20Eme rgency $\% 20$ Use, through $\% 2011 \% 20$ Years $\% 20$ of $\% 20$ Age \& text=Today $\% 2$ C $\% 20$ the $\% 20$ U.S. $\% 20$ Food $\% 20$ and,through $\%$ 2011\%20years\%20of\%20age

155. A.D. Praticò, M. Ruggieri, COVID-19 vaccination for children: may be necessary for the full eradication of the disease. Pediatr. Res. (2021). https://doi.org/10.1038/ s41390-021-01643-y

156. World Bank, Global economic prospects, January 2021. (2021). https://doi.org/10.1596/978-1-4648-1612-3

157. Y. Huang, C. Tan, J. Wu, M. Chen, Z. Wang et al., Impact of coronavirus disease 2019 on pulmonary function in early convalescence phase. Respir. Res. 21(1), 163 (2020). https:// doi.org/10.1186/s12931-020-01429-6

158. A. Jaffri, U.A. Jaffri, Post-Intensive care syndrome and COVID-19: crisis after a crisis? Heart Lung 49(6), 883-884 (2020). https://doi.org/10.1016/j.hrtlng.2020.06.006

159. Z. Tang, N. Kong, X. Zhang, Y. Liu, P. Hu et al., A materials-science perspective on tackling COVID-19. Nat. Rev. Mater. 5(11), 847-860 (2020). https://doi.org/10.1038/ s41578-020-00247-y

160. Z. Tang, X. Zhang, Y. Shu, M. Guo, H. Zhang et al., Insights from nanotechnology in COVID-19 treatment. Nano Today 36, 101019 (2021). https://doi.org/10.1016/j.nantod.2020. 101019

161. S. Danese, B. Sands, S.C. Ng, L. Peyrin-Biroulet, The day after COVID-19 in IBD: how to go back to 'normal.' Nat. Rev. Gastroenterol. Hepatol. 17, 441-443 (2020). https://doi. org/10.1038/s41575-020-0322-8

162. K.B. Habersaat, C. Betsch, M. Danchin, C.R. Sunstein, R. Böhm et al., Ten considerations for effectively managing the COVID-19 transition. Nat. Hum. Behav. 4, 677-687 (2020). https://doi.org/10.1038/s41562-020-0906-x

163. Centers for Disease Control and Prevention, CDC activities and initiatives supporting the COVID-19 response and the President's plan for opening America up again. (CDC, 2020). Accessed 8 November 2021. https://stacks.cdc.gov/view/cdc/ 88478

164. M. Kidd, A. Richter, A. Best, N. Cumley, J. Mirza et al., S-Variant SARS-CoV-2 lineage B1.1.7 is associated with significantly higher viral load in samples tested by TaqPath polymerase chain reaction. J. Infect. Dis. 223(10), 1666-1670 (2021). https://doi.org/10.1093/infdis/jiab082

165. D.A. Collier, A.D. Marco, I. Ferreira, B. Meng, R.P. Datir et al., Sensitivity of SARS-CoV-2 B.1.1.7 to mRNA vaccine-elicited antibodies. Nature 593(7857), 136-141 (2021). https://doi.org/10.1038/s41586-021-03412-7

166. C.K. Wibmer, F. Ayres, T. Hermanus, M. Madzivhandila, P. Kgagudi et al., SARS-CoV-2 501Y.V2 escapes neutralization by South African COVID-19 donor plasma. Nat. Med. 27(4), 622-625 (2021). https://doi.org/10.1038/ s41591-021-01285-x

167. A. Alrubayyi, D. Peppa, Seeing SARS-CoV-2 variants through the eyes of T cells. Nat. Rev. Immunol. 21(5), 274274 (2021). https://doi.org/10.1038/s41577-021-00551-w

168. A. Tarke, J. Sidney, N. Methot, E.D. Yu, Y. Zhang et al., Impact of SARS-CoV-2 variants on the total CD4(+) and CD8(+) T cell reactivity in infected or vaccinated individuals. Cell Rep. Med. 2(7), 100355 (2021). https://doi.org/10. 1016/j.xcrm.2021.100355

169. D. Planas, D. Veyer, A. Baidaliuk, I. Staropoli, F. GuivelBenhassine et al., Reduced sensitivity of SARS-CoV-2 variant Delta to antibody neutralization. Nature 596(7871), 276280 (2021). https://doi.org/10.1038/s41586-021-03777-9

170. B. Bozkurt, I. Kamat, P.J. Hotez, Myocarditis with COVID19 mRNA vaccines. Circulation 144(6), 471-484 (2021). https://doi.org/10.1161/CIRCULATIONAHA.121.056135

171. Centers for Disease Control and Prevention, Selected adverse events reported after COVID-19 vaccination. (CDC, 2021). Accessed 8 November 2021. https://www.cdc.gov/coronavirus/2019-ncov/vaccines/safety/adverse-events.html

172. G. Sinagra, M. Merlo, A. Porcari, Exploring the possible link between myocarditis and mRNA COVID-19 vaccines. Eur. J. Intern. Med. 92, 28-30 (2021). https://doi.org/10.1016/j. ejim.2021.08.018

173. M. Marshall, I.D. Ferguson, P. Lewis, P. Jaggi, C. Gagliardo et al., Symptomatic acute myocarditis in 7 adolescents after Pfizer-BioNTech COVID-19 vaccination. Pediatrics 148(3), 2021052478 (2021). https://doi.org/10.1542/peds. 2021-052478

174. A.K. Verma, K.J. Lavine, C.Y. Lin, Myocarditis after Covid19 mRNA vaccination. N. Engl. J. Med. 385(14), 1332-1334 (2021). https://doi.org/10.1056/NEJMc2109975

175. W.S. Lee, A.K. Wheatley, S.J. Kent, B.J. DeKosky, Antibody-dependent enhancement and SARS-CoV-2 vaccines and therapies. Nat. Microbiol. 5(10), 1185-1191 (2020). https:// doi.org/10.1038/s41564-020-00789-5

176. Y. Zhou, Z. Liu, S. Li, W. Xu, Q. Zhang et al., Enhancement versus neutralization by SARS-CoV-2 antibodies from a convalescent donor associates with distinct epitopes on the RBD. Cell Rep. 34(5), 108699 (2021). https://doi.org/10.1016/j.celrep.2021.108699

177. U.S. Food and Drug Administration, FDA briefing document Pfizer-BioNTech COVID-19 vaccine. (FDA, 2020). Accessed 8 November 2021. https://www.fda.gov/media/144245/downl oad 
178. T. Pilishvili, K.E. Fleming-Dutra, J.L. Farrar, R. Gierke, N.M. Mohr et al., Interim estimates of vaccine effectiveness of Pfizer-BioNTech and Moderna COVID-19 vaccines among health care personnel - 33 U.S. Sites, January-March 2021. MMWR 70(20), 753-758 (2021). https://doi.org/10.15585/ mmwr.mm7020e2

179. S.E. Oliver, J.W. Gargano, M. Marin, M. Wallace, K.G. Curran et al., The advisory committee on immunization practices' interim recommendation for use of Pfizer-BioNTech COVID-19 vaccine - United States, December 2020. MMWR 69(50), 1922-1924 (2020). https://doi.org/10.15585/mmwr. mm6950e2

180. Food and Drug Administration, Fact sheet for recipients and caregivers Emergency Use Authorization (EUA) of the Moderna COVID-19 vaccine to prevent coronavirus disease 2019 (COVID-19) in individuals 18 years of age and older. (FDA, 2021). Accessed 8 November 2021. https://www.fda. gov/media/144638/download\#: : text=The\%20Moderna\%
20COVID $\% 2$ D $19 \% 20$ Vaccine $\% 20$ contains $\% 20$ the $\% 20$ fol lowing\%20ingredients $\% 3 \mathrm{~A} \% 20$ messenger,hydrochloride $\%$ 2C\%20acetic\%20acid\%2C\%20sodium\%20acetate

181. V. Shinde, S. Bhikha, Z. Hoosain, M. Archary, Q. Bhorat et al., Efficacy of NVX-CoV2373 Covid-19 vaccine against the B.1.351 variant. N. Engl. J. Med. 384(20), 1899-1809 (2021). https://doi.org/10.1056/NEJMoa2103055

182. P.T. Heath, E.P. Galiza, D.N. Baxter, M. Boffito, D. Browne et al., Efficacy of the NVX-CoV2373 Covid-19 vaccine against the B.1.1.7 variant. medRxiv (2021). https://doi.org/ 10.1101/2021.05.13.21256639

183. National Institutes of Health, U.S. clinical trial results show Novavax vaccine is safe and prevents COVID-19. (NIH, 2021). Accessed 8 November 2021. https://www.nih.gov/ news-events/news-releases/us-clinical-trial-results-shownovavax-vaccine-safe-prevents-covid-19 